\title{
Lactoferrin in a Context of Inflammation-Induced Pathology
}

\author{
Marian L. Kruzel ${ }^{1}$, Michal Zimecki ${ }^{2}$ and Jeffrey K. Actor ${ }^{1 *}$ \\ ${ }^{1}$ McGovern Medical School, University of Texas, Health Science Center, Houston, TX, United States, ${ }^{2}$ Polish Academy of \\ Sciences, Institute of Immunology and Experimental Therapy, Wrocław, Poland
}

\section{OPEN ACCESS}

Edited by:

Luigi Daniele Notarangelo, Boston Children's Hospital,

United States

Reviewed by:

Stasya Zarling,

Walter Reed Army Institute of Research, United States

Raffaele Badolato,

University of Brescia, Italy

${ }^{*}$ Correspondence: Jeffrey K. Actor jeffrey.k.actor@uth.tmc.edu

Specialty section: This article was submitted to Vaccines and Molecular Therapeutics, a section of the journal Frontiers in Immunology

Received: 24 January 2017 Accepted: 16 October 2017 Published: 06 November 2017

Citation:

Kruzel ML, Zimecki M and Actor JK (2017) Lactoferrin in a Context of Inflammation-Induced Pathology.

Front. Immunol. 8:1438. doi: 10.3389/fimmu.2017.01438
Much progress has been achieved to elucidate the function of lactoferrin (LTF), an iron-binding glycoprotein, in the milieu of immune functionality. This review represents a unique examination of LTF toward its importance in physiologic homeostasis as related to development of disease-associated pathology. The immunomodulatory nature of this protein derives from its unique ability to "sense" the immune activation status of an organism and act accordingly. Underlying mechanisms are proposed whereby LTF controls disease states, thereby pinpointing regions of entry for LTF in maintenance of various physiological pathways to limit the magnitude of tissue damage. LTF is examined as a first line mediator in immune defense and response to pathogenic and non-pathogenic injury, as well as a molecule critical for control of oxidative cell function. Mechanisms of interaction of LTF with its receptors are examined, with a focus on protective effects via regulation of enzyme activities and reactive oxygen species production, immune deviation, and prevention of cell apoptosis. Indeed, LTF serves as a critical control point in physiologic homeostasis, functioning as a sensor of immunological performance related to pathology. Specific mediation of tissue pathophysiology is described for maintenance of intestinal integrity during endotoxemia, elicited airway inflammation due to allergens, and pulmonary damage during tuberculosis. Finally, the role of LTF to alter differentiation of adaptive immune function is examined, with specific recognition of its utility as a vaccine adjuvant to control subsequent lymphocytic reactivity. Overall, it is clear that while the ability of LTF to both sequester iron and to direct reactive oxygen intermediates is a major factor in lessening damage due to excessive inflammatory responses, further effects are apparent through direct control over development of higher order immune functions that regulate pathology due to insult and injury. This culminates in attenuation of pathological damage during inflammatory injury.

Keywords: lactoferrin, immunopathology, immunotherapy, inflammation, pathology

\section{INTRODUCTION}

Over the last several decades, much has been revealed about the nature and function of various immune mediators during the development of host innate immune responses to injury and infection, including cytokines, chemokines, and specific cell surface receptors which trigger a cascade of signaling pathways. There is overwhelming evidence that lactoferrin (LTF), as a first line defense mediator, plays a key role in normalization of insult-induced reactions that disrupt immune homeostasis $(1,2)$. 
Lactoferrin is a highly conserved, monomeric $80 \mathrm{kDa}$ single polypeptide chain contained in most mammalian exocrine secretions, such as milk, saliva and tears, bronchial, and intestinal secretions. LTF is also found in the secondary granules of neutrophils. The primary structure of LTF is well characterized for multiple species (3). LTF is a single polypeptide chain comprised of 692 amino acids organized in two highly homologous structured lobes, which are designated the $N$ - and $C$-lobe. Each lobe is capable of binding a single ferric ion $\left(\mathrm{Fe}^{+++}\right)$. There are two primary forms of human LTF, one is contained within exocrine secretions and the other form is located in the secondary granules of neutrophils; both forms are products of the same gene. While the secreted form is understood as involved in the host defense against microbial infection at mucosal sites, the neutrophilic LTF has additional and distinct immunomodulatory function (4). LTF is a glycoprotein, and in humans the glycans are the $\mathrm{N}$-acetylactosaminic type, described as $\alpha 1,3$-fucosylation on the $N$-acetyl-glucosamine residue which is then linked to the peptide chain. In human LTF, there are three possible $N$-linked glycosylation sites; one site at Asn138, a second at Asn479, and another located at position Asn624. Differential glycosylation at these sites results in distinct variants (5). Many observed activities of LTF (both direct and indirect toward immune regulation) are dependent upon those specific and varied patterns of glycosylation (6). Although there is a high-amino acid sequence homology in species' LTFs the unique glycosylation patterns are likely responsible for heterogeneity of their biological properties. For example, the immunoregulatory human LTF activity is dependent on the interaction of glycoprotein with a receptor specific for sialic acid, with a requirement for sialylation to permit direct lymphocyte activation $(7,8)$. The type of glycosylation on LTF also affects myelopoiesis (9), apoptosis (10), and netosis (11).

Lactoferrin is a first line defense protein for protection against microbial infections $(12,13)$ and subsequent development of systemic disease as seen with systemic inflammatory response syndrome (SIRS) and sepsis (14-16). Clinical importance of LTF to control these processes has been clearly demonstrated through groundbreaking studies on neonates (17-19), where supplementation of diet with LTF reduced occurrence of late onset sepsis. LTF has indeed been proven as a major innate immune responder important in control of the development of acute septic inflammation $(4,14-16,20-22)$. Upon infection, the monocyte/macrophage system responds with the production of inflammatory mediators, which in turn induce bone marrow for generation of new immune cells and activate degranulation of mature neutrophils (Figure 1). Subsequently, a massive amount of LTF is released from the neutrophil's secondary granules to combat the infection. The antimicrobial activity of LTF is well documented and consists of two mechanisms: one is iron dependent and deals with high affinity of LTF to iron (bacteriostatic), and the other one is due to LTF affinity to lipopolysaccharide (LPS) to function as a direct bactericidal agent for Gram-negative organisms. Small changes, such as single nucleotide polymorphisms, can affect outcomes against pathogenic agents $(23,24)$. LTF

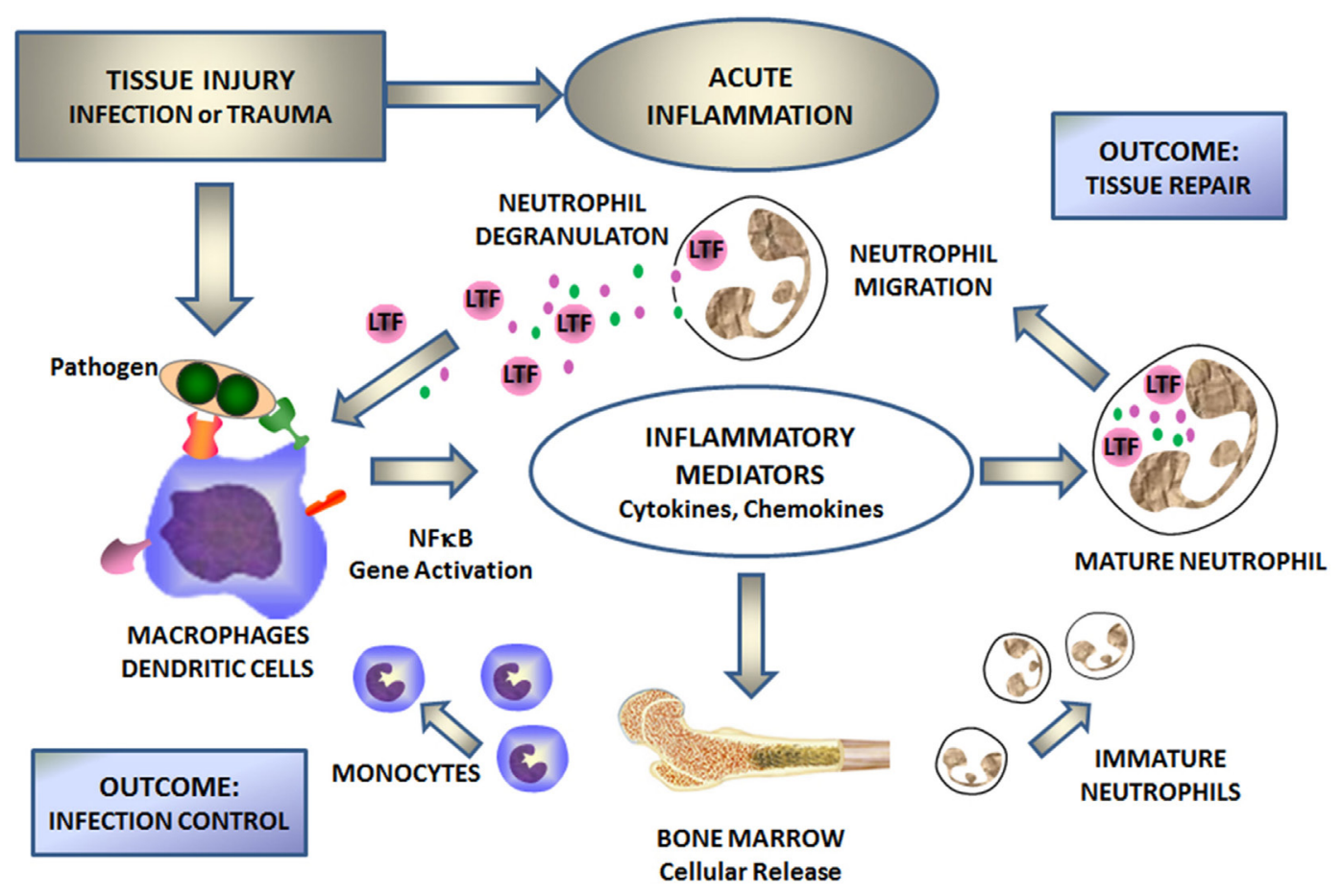

FIGURE 1 | Lactoferrin (LTF) mediates cellular responses to environmental insults. Injury defined by infection, or trauma leads to activation of the NF- $\kappa$ B signal transduction pathway within monocyte/macrophages and/or dendritic cells. This in turn stimulates the production of inflammatory mediators, which subsequently stimulates the production of fresh neutrophils and monocytes from bone marrow and activates circulating neutrophils. Activated neutrophils degranulate to release secondary mediators, including LTF. By interacting with specific receptors on monocytes/macrophages and other immune and non-immune cells, LTF attenuates inflammation and contributes to tissue repair and limits spread of infectious agents. 
interacts with cell surface receptors involved in "danger signal" recognition [e.g., toll-like receptor (TLR)4, CD14, and CD22] (8). By virtue of iron sequestration, LTF can control oxidative burst as macrophages and neutrophils initially respond to injury. In addition, by coupling with various membrane receptors, LTF affects "danger signal" activation of monocytes/macrophages. For example, LTF binding to CD14 receptor competes with the bacterial LPS (product of dying bacteria) (25) and can attenuate $\mathrm{NF}-\kappa \mathrm{B}$-induced transcription of genes for various inflammatory mediators (26). Thus, in part, LTF is mechanistically acting as a feedback mediator for acute inflammation. Figure 1 schematically represents a sequence of events during the development of acute inflammation with LTF as a key mediator.

\section{LACTOFERRIN AS A FIRST LINE DEFENSE MEDIATOR}

In a broader sense, LTF may be classified as an acute phase protein (27) and acts as an "alarmin," a small family of proteins released from neutrophils upon infection $(28,29)$, and playing an important role in altering immune reactivity upon subsequent, pathogenic encounter, or clinical insult. LTF as an alarmin establishes conditional links between neutrophils and dendritic cells (DCs) in a localized space (30). This in turn promotes the maturational switch from innate to adaptive immunity.

Moreover, LTF is a natural adjuvant enhancing immunity to all infectious agents as they are encountered during the period of infancy onward. This begins in vivo with mother's milk; LTF is nature's way to assist in the acquisition and development of protective immunity against infectious-related pathologies during early stages of ontogeny. LTF is involved in a variety of immunoregulatory functions (31-35), ranging from innate immunity enhancement to potentiation of adaptive recall responsiveness (36). It also has associated chemoprotective activity extending to multiple immune cells (37). There is sufficient evidence that LTF ameliorates insult-induced injury and systemically protects integrity of various organs during the development of inflammation (38-42). These findings are critically important in efforts to developing therapeutically relevant protocols to contain the pathological damage caused by specific diseases.

Many reviews have historically focused on LTF as an ironbinding protein involved in defense functions $(43,44)$, with specific analysis on its physical properties $(45,46)$, interaction with specific innate cell phenotypes $(47,48)$, or even receptor interactions that confer pathophysiology (49). For over two decades, our group has also contributed to this platform, with reviews directed toward understanding LTF's involvement in immune modulation $(1,2)$. What is missing from the literature is an assessment of the direct impact of LTF on the development of inflammatory responses to alter outcomes of pathogenesis due to excessive inflammatory responses. Therefore, the objective of this monograph is to review major studies that target the functionality of LTF toward control of insult-induced inflammation and subsequent pathologies. Specific examples will highlight its utility to alter acute pathologies, allowing functional proof for global hypotheses and mechanisms of action attributed to LTF.

\section{INFLAMMATION: AN IMMUNE RESPONSE TO INJURY}

Inflammation is currently viewed as a complex pathophysiologic process that engages literally hundreds of mediators and different cell types in response to microbial or non-microbial injury. Although inflammation is important in tissue repair and/or pathogen eradication, when it is not contained in a timely manner it can be detrimental to the host by establishing systemic and often chronic inflammatory conditions. It is now apparent that the production of primary immune mediators, which include cytokines and chemokines, is dependent on the recruitment of inflammatory cells, particularly innate immune cells such as neutrophils, macrophages, and DCs. Cellular activation leads to release of secondary immune mediators and subsequent induction of the adaptive immune responses (50). In parallel, the complement system, an assembly of soluble enzymatic proteins and peptides in the blood and body fluids, actively regulates these inflammatory responses (51), many of which are identified as contributing toward regulation of higher immune function (52). The multiple interconnections among immune cells, cytokines, chemokines, and complement proteins protect against development of systemic infections and support damaged tissue repair.

Here, we review the role of LTF innate immune functions critical during the inflammatory responses which drive development of pathology. Our discussion begins with a presentation of inflammation in response to environmental insult, thus introducing entry points for LTF with the overall goal to identify mediation and subsequent control to limit pathological damage. Inflammation is a protective strategy that functions to remove a harmful stimulus, typically infectious agents. Inflammation also contributes to ultimate repair of damaged tissue, even in the absence of infection. In fact, "sterile" inflammation is a natural response elicited during tissue damage or excessive cell death (53). Acute inflammation, which occurs immediately after injury, may subsequently progress to chronic conditions if the initial response cannot be quickly resolved, either because of the persistence of the injurious agent, or due to impairment of the individual's immune system. Typically, acute inflammation is regarded as local vasodilation and increased vessel permeability to improve blood flow and deliver molecules and cells to help repair injured parenchyma. In contrast, chronic inflammation is characterized by simultaneous or cycling destruction and subsequent healing processes over time in tissue undergoing constant and repetitive damage.

Both conditions of infection and sterile tissue injury generate a strong immune response induced by a sequence of events that originate from dying/injured or infected cells, resulting in release of proteins and bio-active compounds. These endogenous factors are known as cell death-associated molecular patterns or damage-associated molecular pattern (DAMP), or pathogenassociated molecular pattern molecules [reviewed elsewhere in detail $(51,52)]$. These molecules are expressed by immune and non-immune cell types and are derived from their cytosol, nuclear, or mitochondrial compartments. These are exemplified by IL- $1 \alpha$ (nucleus), ATP, S100 proteins, high-mobility group box 1, and uric acid (cytoplasm), formyl peptides, heat shock 
proteins (exosomes), mDNA (mitochondria), heparan sulfate, and hyaluronan fragments (extracellular matrix). These endogenous "danger signals" have the affinity for diverse cell receptors; their binding initiates coupled signaling pathways that activate inflammasome platforms and NF- $\mathrm{BB}$ multiprotein complexes (54) (Figure 2). LTF, like many other human milk proteins, clearly contains multiple entry points for interaction with innate receptors that mediate downstream activities related to "danger signals" (55). LTF can specifically interact with cellular receptors that sense these "danger signals," and therefore influence innate system cells; thus serving as a mediator to migration and maturation of subsequent immune responses (48). It is readily accepted that TLRs represent a key molecular link between any type of injury and subsequent development of inflammation. This in turn leads to maturation of subsequent immune responses in a controlled manner (56). For example, LTF reduced the synthesis of chemoattractants, such as IL-8 and monocyte chemoattractant protein- 1 that were induced by viral infection in macrophages, by way of suppression of NF- $\mathrm{BB}$ activity. LTF is perhaps best known for its interaction with accessory molecules, such as CD14, and upregulates CD40 after interaction with TLR4 (57). Furthermore, LTF has been demonstrated to neutralize free LPS by disrupting formation of complexes to activate the TLR4 signaling pathways (58). Likewise, LTF also interacts with TLR2 to interfere with molecular processes upstream of NF- $\kappa B$ activation. And it was reported that LTF was able to inhibit TLR9 recognition of dsDNA via binding to its co-receptor CD14 (59). In addition, LTF interacts with CD22 (8), and by doing so, it could reverse a methotrexate-induced suppression of the secondary immune responses of mouse splenocytes to antigen; the immunorestorative activity was dependent on the interaction of LTF with the CD169 sialoadhesin. It is therefore likely that LTF also plays an indirect role through other "sensing" receptors, such as the receptor for advanced glycation end products (RAGE) and the myeloid cell triggering receptor TREM-1. These are less prominent, but stimulation through these receptors also triggers NF- $\mathrm{kB}$ activation and subsequent transcription of genes for inflammatory cytokines and chemokines $(60,61)$. This includes expression of IL- $1 \alpha$ and $\beta$, IL-6, IL- 8 , TNF- $\alpha$, IL-12, IL-15, IFN- $\alpha$, and IFN- $\beta$, cyclooxygenases (COX1 and COX2), and inducible nitric oxide (nitric oxide) synthase; they also include the gene products important for initiation of adaptive immune responses (such as CD80, CD86, and CD40) (62). These diverse mediators initiate a cascade of specific and non-specific responses including bone marrow stimulation for the production of monocyte and neutrophil precursors (Figure 1) (61). Finally, it should be mentioned that LTF can also activate complement, through the classical pathway, which assists in mediating attraction of innate cells to inflammatory sites (63). However, conflicting data demonstrate that LTF can block deposition of C3 and C5 complement components (64). Indeed, LTF-derived peptides have been shown to exhibit anti-classical complement pathway effects (65).

Neutrophils directly produce LTF, which upon release plays a pivotal role in the development and resolution of inflammation. LTF also increases the activity of cathepsin G, a known antibacterial enzyme (66), and broadens its substrate specificity (67), suggesting that LTF acts in concert with antibacterial

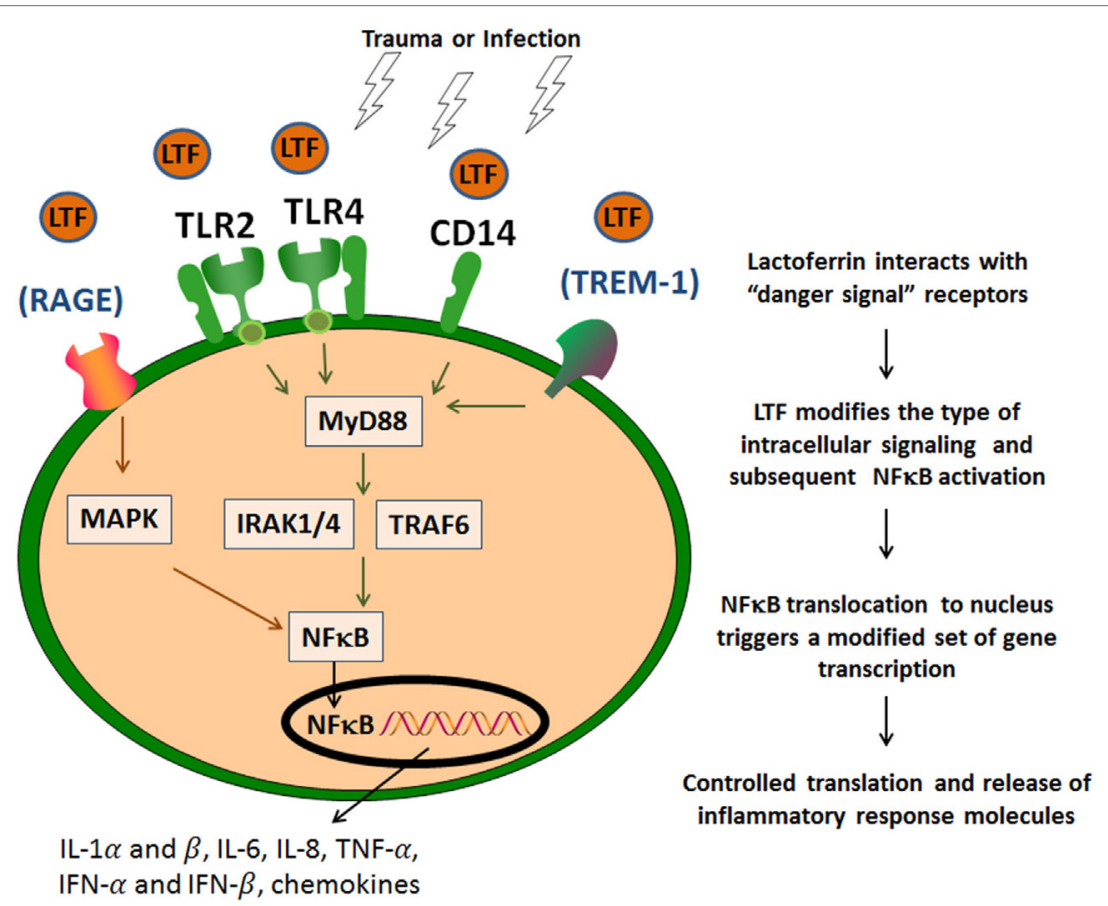

FIGURE 2 | Lactoferrin (LTF) affinity to "danger signal" receptors. LTF modifies the type of intracellular signaling and subsequent NF-kB activation via identified danger signal receptors [toll-like receptor (TLR)2, TLR4, and CD14]. This results in a modified subset of proteins to control and contain the inflammatory response. LTF may also act via other additional signaling receptors, such as RAGE or TREM-1, which also utilize NF-кB activation pathways. 
neutrophil-derived enzymes in the initial phase of infection. However, it should be noted that there is a relative feedback loop; LTF released from neutrophils can effectively reduce neutrophil extracellular traps, important in overall inflammatory response (11). It is only secondary to neutrophilic release of LTF that macrophages, under conditions of inflammatory insult, are modified in responding action. LTF can modify iron homeostasis, which is critical for responsiveness to bacterial insult and subsequent inflammation (68).

\section{Lactoferrin Controls the Oxidative Cell Injury}

By virtue of iron sequestration, LTF controls the physiological balance of production of reactive oxygen species (ROS) and rate of their elimination, which naturally buffers against direct oxidative cell injury. One strong hypothesis is that by controlling oxidative stress, LTF modulates innate immune responsiveness which alters production of immune regulatory mediators that are important for directing development of adaptive immune function. Indeed, many investigators have shown that LTF exhibits profound modulatory action on the adaptive immune system $(34,35,44,69)$, as we detail below; it is likely this stems from effects of early innate responses related to development of oxidant species. We have specifically identified that LTF has a significant regulation on cellular redox via upregulation of key antioxidant enzymes (70).

Oxidative stress is implicated in multiple chronic degenerative processes including those which affect the development of cancer and neurodegenerative disorders, atherosclerosis, inflammation, and aging, and even defense against infection (71-73). Many of the exact oxidant species that are produced during metabolic reactions are still being researched. In many instances, the factor(s) of physiological or pathophysiological significance causing a sustained ROS production imbalance that results in subsequent establishment of oxidative stress in vivo remain undefined. What is known is that the rate and magnitude of ROS formation and their elimination under normal physiological conditions is highly dependent on efficiency of superoxide dismutase (SOD), catalase (CAT), and glutathione peroxidase (GPx). While SOD converts superoxide radical $\left(\cdot \mathrm{O}^{-2}\right)$ into hydrogen peroxide $\left(\mathrm{H}_{2} \mathrm{O}_{2}\right)$, the other two enzymes, GPx or CAT, transform this highly reactive hydrogen peroxide into water $\left(\mathrm{H}_{2} \mathrm{O}\right)$ or water, and molecular oxygen $\left(\mathrm{O}_{2}\right)$, respectively. However, in a presence of free ferric ions $\left(\mathrm{Fe}^{3+}\right)$ the superoxide radical may go under two-step, non-enzymatic, degradation process (Figure 3). In the first reactive step, a superoxide molecule reacts with ferric ion $\left(\mathrm{Fe}^{3+}\right)$ to form ferrous salt $\left(\mathrm{Fe}^{2+}\right)$ and the ground state oxygen. In a second step, known as the Fenton reaction, ferrous $\left(\mathrm{Fe}^{2+}\right)$ ions react with hydrogen peroxide to form ferric salt $\left(\mathrm{Fe}^{3+}\right)$, a hydroxyl radical, and an alcohol. The formation of hydroxyl radical via an iron-dependent reaction is strongly implicated microbicidal activity within phagocytes and lipid peroxidation events (particularly polyunsaturated fatty acids). The reaction of the hydroxyl radical with polyunsaturated fatty acids results in the abstraction of a hydrogen atom. This initiates lipid peroxidation, and the production of intermediates such as hydroxyalkenals, to realize new radicals to potentially induce functional changes in multiple macromolecules of biological importance. These macromolecules include DNA, proteins, and lipids (74). By virtue of sequestering ferric $\left(\mathrm{Fe}^{3+}\right)$ ions, LTF protects against the damaging effects of oxidative stress.

\section{LTF Prevents Reduction of Ferric Iron $\left(\mathrm{Fe}^{3+}\right)$ to its Ferrous $\left(\mathrm{Fe}^{2+}\right)$ State}

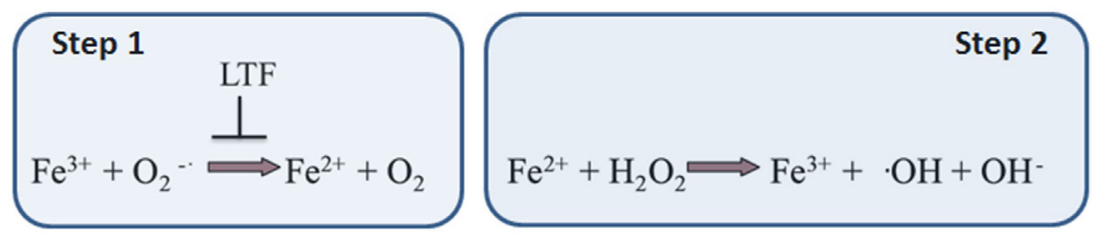

By Limiting the Production of ROS, LTF Prevents Subsequent Cellular Damage

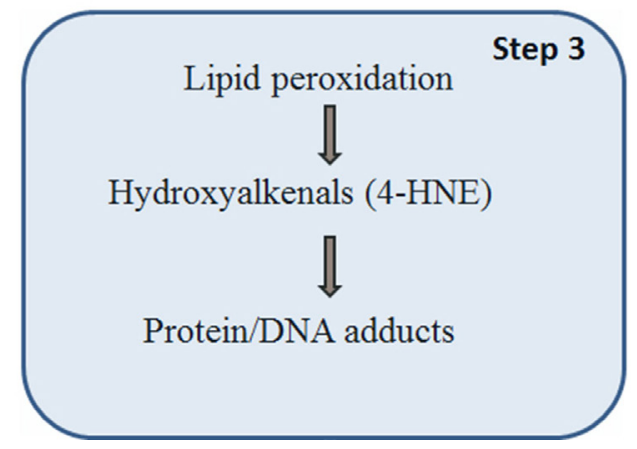

FIGURE 3 | Lactoferrin (LTF) protects against oxidative stress-induced cellular damage. LTF inhibits free ferric $\left(\mathrm{Fe}^{3+}\right)$ ions reactivity with superoxide molecules, thus limiting formation of ferrous $\left(\mathrm{Fe}^{2+}\right)$ salt and ground state oxygen (step 1). In turn, there is reduced reactivity of ferrous $\left(\mathrm{Fe}^{2+}\right.$ ) ion with hydrogen peroxide to form ferric $\left(\mathrm{Fe}^{3+}\right)$ salt, a hydroxyl radical, and an alcohol (step 2). The end result is that LTF protects against oxidative stress, in particular by limiting the production of hydroxyl radical and lipid peroxidation (step 3). 
Lactoferrin contributes to general homeostasis by disrupting the production of these metabolically active molecules (70). This has been demonstrated in models of tissue trauma. Okazaki et al. (26) investigated the antioxidant property of bovine LTF (bLTF) in the rat model of ferric nitrilotriacetate-induced renal tubular oxidative injury. In this study, LTF suppressed both urea nitrogen levels in the blood and elevation of serum creatinine. Protective effects against renal oxidative tubular damage were seen, as well as maintenance of antioxidant enzyme activities in the bLTF-pretreated group. The authors suggested that LTF intake is beneficial for the prevention of iron-mediated renal tubular oxidative damage.

Also, in earlier studies on endotoxemic mice, it was demonstrated that LTF decreased levels of intracellular oxidative stress induced by LPS through reduction in mitochondrial dysfunction (75). In that particular study, LTF attenuated mitochondrial dysfunction within the liver of LPS-treated animals. This was demonstrated by reduced release of $\mathrm{H}_{2} \mathrm{O}_{2}$ from mitochondria, as well as a significantly lowered associated mitochondrial DNA damage. This supports a growing body of evidence that LTF can modulate cellular damage and death induced by acute inflammation. Apoptotic and necrotic cell death are two consequential activities critical to development of SIRS and sepsis-related pathology. These are tightly associated with mitochondrial dysfunction that is often characterized by increased production of ROS and increased membrane permeability, loss of mitochondrion integrity, and alterations in levels cellular ATP. Mitochondrial dysfunction and attendant bioenergetics defects are indeed increasingly becoming recognized as important role players in many chronic and acute disorders (75).

\section{LACTOFERRIN AND GENERAL PHYSIOLOGIC HOMEOSTASIS}

Homeostasis is the maintenance of equilibrium in a biological system by means of feedback via control mechanisms which counteract physiological dissonance and/or development of pathology. At the molecular level, homeostasis is controlled by a neuro-endocrine-immune system network wherein LTF plays a central role, largely due to its above-mentioned ability to bind ferric ions. Iron indeed is the most abundant trace mineral found within the body and it plays an essential role in most biological systems. Iron is a vital component of the heme in myoglobin, in hemoglobin, and in cytochromes. Iron is also an essential cofactor for many non-heme enzymes, including ribonucleotide reductase which is a limiting enzyme for DNA synthesis (76). However, free iron is also toxic in that it has a strong potential to induce formation of "dangerous" free radicals. Consequently, iron homeostasis is tightly regulated, in part by LTF, which plays a role of "safety net" protecting against oxidative stress to reduce the magnitude and the structure of insult-induced cellular damage.

\section{Lactoferrin As a Sensor of Immune Status in Humans}

Lactoferrin is a pleiotropic agent involved as an in vivo "immune sensor" directing specific immune responses to acquire immune homeostasis (2). However, one of the key questions emerging from studying the pleiotropic immune activities of LTF in vivo is a determination of factors that drive LTF to exhibit directed anti- or pro-inflammatory parameters. In a human volunteer study, orally administered bLTF (40 mg/day) showed differential effects on immune responsiveness of peripheral blood mononuclear cells (PBMC) (2). Healthy individuals were evaluated for the effects of LTF on the mitogenic proliferative response of PBMCs, and the ability of whole blood cultures to produce IL- 6 and TNF- $\alpha$ upon LPS activation. Two categories of individuals were identified (high and low responders) based on immune responsiveness of PBMCs to secrete IL-6 (Figure 4). Another group was selected according to relative production of TNF- $\alpha$. The in vivo effects of LTF appeared to be dependent upon the baseline immune status of a given individual. Down-regulatory activity of LTF was identified after treatment in the high-responding individuals, while the lower-responding group showed that LTF had upregulatory effects. To a much greater extent, LTF affected spontaneous production of TNF- $\alpha$ and IL- 6 by PBMCs. It is known that cytokine production is dependent on interaction via cell-to-cell receptors (77), which include the accessory adhesion molecules such as LFA-1. Indeed, experimental models demonstrated that LTF has regulatory effects on cytokine production that is linked to modulation of LFA-1 surface expression (35). A third parameter was identified in which a twofold increase in the content of neutrophil precursors in the circulating blood was noticed after oral treatment of volunteers with LTF was (not shown). It has been suggested that the dichotic responses seen in individuals are related to genetic polymorphisms present within the population (24, 78-80).

The immunoregulatory and protective activities of LTF were subsequently established in mice (81) and patients (82) subjected to surgery. In the first case, LTF significantly reduced levels of TNF- $\alpha$ and IL- 6 , elicited by abdominal surgery. In the patients, in turn, LTF prevented postsurgical hyporeactivity of peripheral blood lymphocytes, typically observed 1 day following surgery. Intraperitoneal and intravenous routes of LTF administration ensure rapid and undisturbed interaction of target cells with undigested LTF. With that in mind, the numerous immunoregulatory effects of LTF when given orally or buccally require particular attention and a plausible mechanistic explanation. It appears that LTF has the potential to interact with several cell types contained in oral mucosa. Epithelial DCs (83), keratinocytes (84), and oral epithelial cells (85) bear CD14 and TLRs able to recognize LTF. More importantly, LTF can trigger maturation of DCs through TLR2 and TLR4 (86), with such events known to promote DC migration to adjacent lymph nodes (87). Orally ingested LTF may also interact with intestinal epithelial cells expressing TLRs (88). Thus, the immunoregulatory effects of oral LTF may originate from its interactions with target cells located in the sublingual and buccal regions of the oral cavity. Most probably, LTF bearing DAMP characteristics transmits "danger" signals by DC into peripheral lymphoid tissue. LTF may not only transmit direct signals upon interaction with mucosal cells, but may also penetrate target organs $(55,89)$, such as seen after high-systemic oxidative stress (90). However, further studies are required to explain how these DC communicate with other immunocompetent cells to change their activation status. In a more recent study, we evaluated effects of homologous, recombinant human LTF (rhLTF) on 


\section{Effect of Lactoferrin on Spontaneous} Production of IL-6 by PMBC

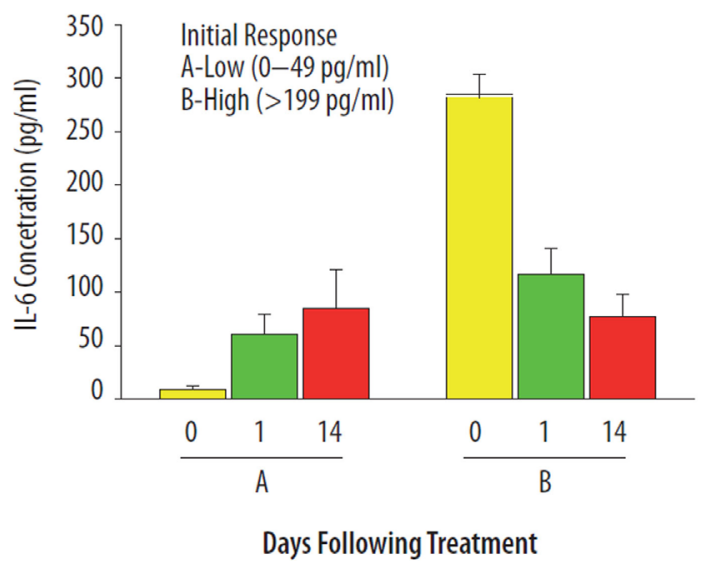

Effect of Lactoferrin on Spontaneous Production of TNFa by PMBC

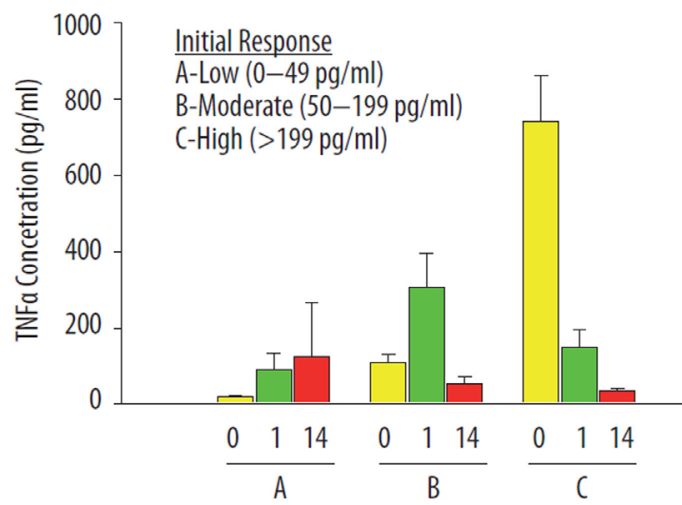

Days Following Treatment

FIGURE 4 | Immunoregulatory effects of lactoferrin (LTF) on the spontaneous production of IL-6 and TNF- $\alpha$ from human PMBCs. Healthy volunteers were given one capsule containing $10 \mathrm{mg}$ of LTF, daily for 7 days. Blood samples were examined prior to the first dose, and again 1 and 14 days after administration of the last dose of LTF. The spontaneous production of IL-6 (left) and TNF- $\alpha$ (right) from blood cells was determined by bioassay after $24 \mathrm{~h}$ whole blood culture incubation. The data presented have been published previously, in Kruzel et al. (2), reprinted with permission.

the reactivity of whole blood cells derived from patients admitted to the ICU because of surgical, medical, or trauma reasons (91). Some of the patients developed septic shock. The effect of LTF was investigated with regard to LPS-induced TNF- $\alpha$ production following admission to ICU. The patients showed, in majority, a deep hyporeactivity to LPS upon admission. The rhLTF exerted differential effects on production of LPS-induced TNF- $\alpha$ in those patient's whole blood cell cultures. The cytokine production was upregulated only in patients with sustained anergy to LPS, and inhibited or unchanged in moderately reactive patients.

\section{Lactoferrin Protects Intestinal Integrity during Endotoxemia}

For many years, it has been known that LTF has protective action to limit irritation within subcutaneous tissues and internal organs. For example, oral treatment of rats with bLTF inhibited carrageenan-induced paw inflammation in rats (41). LTF inhibition of the skin inflammation was associated with a profound decrease in the ability to produce LPS-induced IL-6.

There is expanding evidence to show that progression of SIRS into sepsis is due to cellular damage caused by acute inflammatory responses $(92,93)$. The cell death during these events is in part due to mitochondrial dysfunction, often characterized by increased production of ROS (94). LTF is a critical component involved in mediation of this response, so as to allow controlled regulation of inflammation without rapid induction of pathological damage. The mechanism of action for LTF contains multiple components for differential regulation of cellular immune responses during the development of SIRS. Bacteremia and endotoxemia manifest as severe clinical syndromes characterized by pro-inflammatory cytokine release, massive release of ROS, and increased adhesion molecule expression $(95,96)$. In particular, the systemic inflammatory response directed toward bacterial LPS includes production and liberation of pro-inflammatory cytokines from gut-associated lymphoid tissue, which in turn affects gut mucosal permeability. This subsequently contributes to enteric bacterial translocation to distant sites (97-100). As demonstrated in mice, intraperitoneal administration of LTF at $1 \mathrm{~h}$ prior to LPS injection significantly enhanced survival and reduced mortality from 83.3 to $16.7 \%$ (20). Similar protective effects have been reported by Zagulski et al. using live Escherichia coli (101). Histological examination of intestinal segments revealed remarkable differences between LTF-pretreated endotoxemic mice and LPS counterpart. Severe vacuolar degeneration of jejunal epithelium observed in LPS-treated mice was significantly reduced in mice treated with LTF [Figure 5; previously published and described in detail by Actor et al. (1)]. Clearly, LTF has an impact on gut mucosal integrity and function (102). Mice treated with LPS quickly become hypothermic; pretreatment with LTF allowed a less pronounced drop in body temperature. Development of hypothermia in those LPS-treated mice also correlated with severe lethargy; LTF-treated mice expressed normal behavioral activities. At the molecular level, LTF seems to reduce LPSinduced monocyte activation and subsequent production of proinflammatory mediators. Similarly, rats given LTF to modulate LPS treatment showed marked moderation of hypotension and alleviation of histopathological damage to intestinal tissue (103). Proof of concept models using E. coli and/or MRSA infection have been detailed $(1,104-106)$; administration of LTF resulted in uniform inhibition of TNF- $\alpha$, IL-6, and IL-10, as well as reduction in NO. Of high interest, prophylactic administration of LTF resulted in similar decreases in both TNF- $\alpha$ and NO. Similarly, LTF given $18 \mathrm{~h}$ postinduction of endotoxic shock gave nearly identical results (1). The mechanisms of action for LTF to protect gut integrity appear to contain multiple components for 
differential regulation of cellular immune function during in vivo models of sepsis in both mice and rats. In fact, a strong resulting hypothesis was put forth that the protective effects of LTF result from generalized deactivation of the macrophage population, which is manifested by significant suppression of both pro- and anti-inflammatory mediators $(1,16,20)$.

Similar pathological changes in organs, associated with inadequate inactivation of intestinal LPS, have been reported by ligation of bile duct (107). A complete deprivation of bile (s-IgA and containing bile salts) from the gut lumen leads to loss of mucosal integrity, and decreased endotoxin inactivation in the endogenous bacterial flora. The result is portal bacteremia and endotoxemia, as well as increased bacterial translocation to mesenteric lymph nodes. In an experimental model, we evaluated effects of bLTF, on liver histopathology in obstructive jaundiced (OJ) rats and the production of LPS-induced TNF- $\alpha$ and IL-6 by splenocytes (108). Table 1 summarizes the effect of LTF on the intensity of induced OJ. In rats with 14-day OJ, treated with bLTF, the changes in the liver pathology were markedly reduced

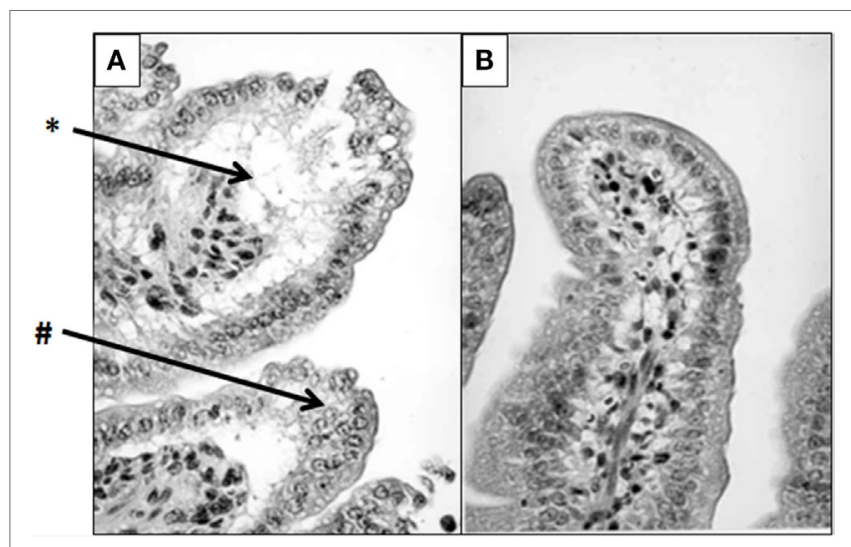

FIGURE 5 | Lactoferrin (LTF) protects against lipopolysaccharide (LPS)induced damage to mouse intestinal structures. LTF administered intraperitoneally prior to injection of LPS significantly limited damage to intestinal microvilli. High-power micrographs reveal that the saline/ LPS-treated mice (A) demonstrate severe villus atrophy (\#), edema, and epithelial vacuolation $\left(^{*}\right)$ compared with the LTF-treated counterparts (B) Tissue was stained with hematoxylin and eosin as described in Ref. (1). Photomicrographs were previously described in detail, and published in Actor et al. (1). Visualized at $400 \times$ magnification. in multiple parameters that included limitation of necrotic foci with disseminated lymphocytes, and reduced cellular necrobiosis and bile duct proliferation and dilation. Concurrent with this was an absence of proliferation of fibrous and reticular connective tissue or Kupffer cell activation. In these rats, LTF upregulated cytokine production, in particular spontaneous and LPS-induced TNF- $\alpha$ indicated a reversal of LPS hyporeactivity caused by long-time endotoxin exposure. Innate immunity parameters in the small intestine may be upregulated by LTF, shown in mice subjected to immobilization stress (109). Other studies were devoted to evaluate protective effects of bLTF on colitis induced by application of non-specific chemical irritants. In a model of trinitrobenzenesulfonic acid (TNBS)-induced colitis in rats (110), daily gavage of LTF attenuated TNBS-induced colitis as assessed by macroscopic and histologic scoring and myeloperoxidase activity. The anti-inflammatory cytokines IL-4 and IL-10 were upregulated whereas pro-inflammatory TNF- $\alpha$ and IL- $1 \beta$ were suppressed. Similar results were obtained in a model of dextransulfate-induced colitis in BALB/c mice (111). In this study, the treatment of mice with apo-LTF (iron-free) gave better results than that with holo-LTF (iron saturated). Very recent findings also indicate that in the model of dextran sodium sulfate induced colitis, LTF protects gut integrity by increasing $\mathrm{T}$ regulatory cell population in intestinal lamina propria (112).

Intestinal ischemia-reperfusion injury $(\mathrm{I} / \mathrm{R})$ is a serious clinical condition, also affecting gut integrity. A study examined LTF for its properties to attenuate I/R in rats (113). Under non-treated conditions, $\mathrm{I} / \mathrm{R}$ is reflected by morphological alteration, reduction of $\gamma$-glutamyl transpeptidase ( $\gamma$-GGT) activity, and increased cell apoptosis. In these studies, I/R damage was achieved by an occlusion of the superior mesenteric artery. Daily administration of LTF for 14 days before surgical intervention significantly attenuated gut damage reduced the histologic score and apoptosis index. LTF treatment restored intestinal $\gamma$-GGT activity, reduced intestinal malondialdehyde, and myeloperoxidase levels, reestablished glutathione levels, and lowered serum levels of pro-inflammatory cytokines. Orally ingested bLTF also protected intestinal damage elicited by experimentally induced hepatitis (39).

Among many therapeutic applications of LTF in humans, bLTF, ingested daily for a period of 1 year in a high dose $(3 \mathrm{~g})$, suppressed colorectal polyps growth in patients (114). The patients with regressing polyps had increased NK cell activity and increased autologous LTF serum levels. The polyps showed the

TABLE 1 | Type and degree of changes in livers of rats with obstructive jaundice.

\begin{tabular}{|c|c|c|c|c|c|c|c|c|c|}
\hline Type of change & Treatment & Mean & Median & Statistics & No change & $\begin{array}{c}\text { Light } \\
\text { change }\end{array}$ & $\begin{array}{c}\text { Moderate } \\
\text { change }\end{array}$ & $\begin{array}{c}\text { Significant } \\
\text { change }\end{array}$ & Tota \\
\hline \multirow[t]{2}{*}{ Foci with necrosis with disseminated lymphocytes } & Control & 2.29 & 9.73 & $p \leq 0.001$ & 0 & 2 & 6 & 6 & 32 \\
\hline & LTF & 0.17 & 0.39 & & 10 & 2 & 0 & 0 & 2 \\
\hline \multirow[t]{2}{*}{ Necrocytosis of single hepatocytes } & Control & 1.29 & 0.61 & $p \leq 0.001$ & 0 & 11 & 2 & 1 & 18 \\
\hline & LTF & 0.25 & 0.45 & & 9 & 3 & 0 & 0 & 3 \\
\hline \multirow[t]{2}{*}{ Proliferation of the bile ducts with their dilations } & Control & 2.29 & 0.73 & $p \leq 0.001$ & 0 & 2 & 6 & 6 & 32 \\
\hline & LTF & 0.58 & 0.51 & & 5 & 7 & 0 & 0 & 7 \\
\hline \multirow[t]{2}{*}{ Proliferation of fibrous and reticular connective tissue } & Control & 1.00 & 0.00 & $p \leq 0.001$ & 0 & 14 & 0 & 0 & 14 \\
\hline & LTF & - & - & & 12 & 0 & 0 & 0 & 0 \\
\hline
\end{tabular}

Changes seen in liver tissue samples were scored as none, light, moderate, and significant, as described (108). The non-parametric Mann-Whitney's test was applied to data, with results given as mean and median values. Significant differences are indicated; $n \geq 12$ per group. Data previously published by Zimecki et al. (108). 
presence of $\mathrm{CD}^{+}$and $\mathrm{CD} 161^{+}$cells, suggesting that infiltrating $\mathrm{T}$ and NK cells play a role in tumor destruction. Taken together, LTF exhibits protective functions in jejunum, colon, and liver of experimental animals exposed to bacterial products or chemical irritants by means of several mechanisms, all of which appear related to control of ROS.

\section{Lactoferrin Ameliorates Pollen Antigen-Induced Airway Inflammation}

Oxidative stress in asthma is a consequence of enhanced ROS generation by inflammatory cells recruited to airways upon concurrent exposure to pro-oxidant environmental molecules (ozone, cigarette smoke, etc.), or to respiratory viral infections $(115,116)$. We have previously shown that pollen grains and their extracts, such as ragweed pollen (RWE), generate $\mathrm{O}_{2}^{-}$because of reduced $\mathrm{NAD}(\mathrm{P}) \mathrm{H}$ oxidase activity, essential for robust airway inflammation generated in the mouse $(117,118)$. Although $\mathrm{O}_{2}^{-}$ and $\mathrm{H}_{2} \mathrm{O}_{2}$ are considered as signaling molecules (119), their conversion to ${ }^{\circ} \mathrm{OH}$ by free iron is important in induction and augmentation of inflammatory processes. Pro-oxidant iron is present in airway lining fluids, as well as in resident cells of airways of human and animals. This pro-oxidant iron mediates oxidative stress in the lungs (120-123). LTF can certainly modify iron homeostasis, critical for responsiveness to bacterial insult, and subsequent inflammation, as discussed previously (68). We demonstrated that LTF, as an iron-binding protein, ameliorated (RWE)-induced airway inflammation. Interestingly, only apo-LTF (iron free), but not the iron-saturated holo-LTF form significantly lowered accumulation of inflammatory cells and formation of mucin-producing cells in airways induced by pollen extract [Figure 6; previously published and described in detail by Kruzel et al. (38)].

The utility of LTF to limit and contain ovalbumin-induced pleurisy in BALB/c mice was studied (124). Pulmonary histologic analysis showed that LTF diminished pathological lesion development, including diffuse alveolar hemorrhage and hemosiderosis and accumulation of pulmonary edema, which were common in control lungs after injection of the eliciting dose of ovalbumin. LTF also decreased the amounts of IL-5 found secreted into pleural fluid, suggesting a skewing of immune reactivity to $\mathrm{T}_{\mathrm{H}} 1$ type. This was a first demonstration that LTF significantly decreased

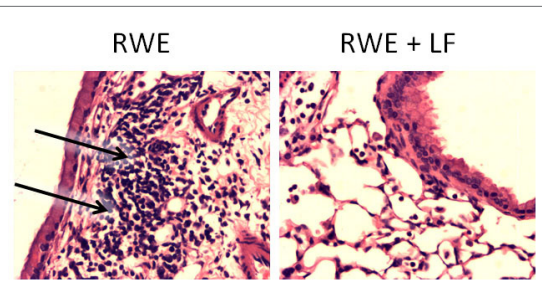

FIGURE 6 | Effect of lactoferrin (LTF) on ragweed pollen (RWE)-induced accumulation of inflammatory cells into subepithelium. Mice challenged with RWE demonstrated high-inflammatory cell infiltrates within peribronchial region (arrows) postchallenge (left), but not in the LTF-treated mice (right). Sections were stained with hematoxylin and eosin and visualized at 100x magnification. Photomicrographs were previously described in detail, and represent studies published in Kruzel et al. (38). antigen-specific pleurisy in a sensitized mouse model. The finding findings were confirmed and extended by others who showed increases in IFN $\gamma$ but decreases of IL-5, 10, 17, and TGF $\beta 1$ production which are typical markers for $\mathrm{T}_{\mathrm{H}} 2$ and $\mathrm{T}$ regulatory cells function and development (125). An alternate explanation includes the ability of LTF to inhibit eosinophil migration during allergic rhinitis and asthma (126).

\section{Lactoferrin Ameliorates Tuberculosis (TB)-Induced Lung Pathology}

Lactoferrin has been shown to have therapeutic function to alter destructive pathology in models of TB. Specifically, LTF was able to modulate granulomatous responses, without significant loss of production of known early induced pro-inflammatory mediators (TNF- $\alpha$, IL-1 $\beta$, and IL-6) requisite for control of infectious organisms. Treatment with LTF showed statistically significant fewer granulomas compared with mice given mycobacterial cord factor (glycolipid trehalose 6,6' -dimycolate; TDM) alone (42), and granulomas were significantly reduced in size and complexity. The utility of oral delivered LTF was also demonstrated with statistically significant reduction in histopathology post-TDM administration in $\mathrm{BALB} / \mathrm{c}$ and $\mathrm{C} 57 \mathrm{Bl} / 6$ mice [Figure 7; representative data shown only for $\mathrm{C} 57 \mathrm{Bl} / 6$ mice; data previously published by Welsh et al. (42)]. The oral delivered LTF demonstrated biologically relevant reduction in pathology, similar to that seen in the published results using intravenous administered rhLTF (127).

We have previously reported that classical cytokines critical for control of Mycobacterium tuberculosis (MTB), namely TNF- $\alpha$, IL-6, and IFN- $\gamma$, were not statistically altered by LTF treatment (41). In one experiment, we gave LTF administered in drinking water to mice aerosol infected with virulent mycobacteria (41). The bacterial load in tissue was only slightly reduced; however, the major change was amelioration of granulomatous severity. It is noteworthy that this activity was accompanied by an increase in classical pro-inflammatory mediators while decreasing overall lung immune-histopathology (41). Specifically, the LTF-treated animals increased presence of helper $\mathrm{CD} 4^{+}$IFN- $\gamma^{+}$and IL-17 producing cells in lung tissue. The LTF by itself was not bactericidal, instead, the LTF was shown to augment IFN- $\gamma$ mediated macrophages killing of MTB by in an NO-dependent manner. As a clinical outcome, these studies suggest strongly that LTF can be a novel therapeutic for TB treatment. The limitation of pathology and tissue damage postinfection would in essence create a "firebreak" to slow transmission within a community. The data presented in those studies indicates that LTF protects against excessive pathological changes and should be considered when discussing novel therapeutic protocols for the treatment of TB.

\section{Lactoferrin Mediates Differentiation of Adaptive Immune Function}

It is becoming increasingly clear that LTF plays a role central to the development and full expression of adaptive host immune responses. LTF has demonstrated profound modulatory activity on the adaptive immune system $(34,35,69)$ by promoting maturation of $\mathrm{T}_{\mathrm{H}} 0$ cells ( $\mathrm{T}$-cell precursors) into competent helper cells. LTF was also able to accelerate differentiation of immature 


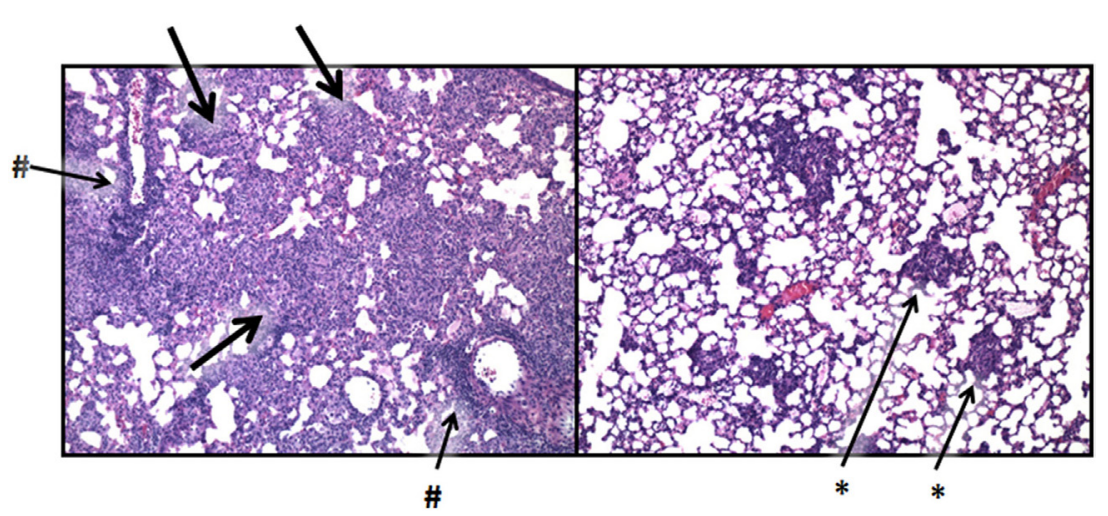

FIGURE 7 | Lactoferrin (LTF) modulation of the mycobacterial granulomatous response. C57BL/6 mice were challenged with mycobacterial glycolipid trehalose 6,6'-dimycolate (TDM) prepared as described (42). TDM induces severe granulomatous responses comprised of activated monocyte/macrophages, with peak inflammatory response shown postinjection (left). Aggressive granulomatous response includes large mononuclear cell accumulation (thick arrows) and severe lymphocytic perivascular cuffing (\#). Administration of LTF at 1 day postchallenge nearly abolishes the pro-inflammatory response, and restores normal lung architecture (right), with only focal residual monocytic infiltrates remaining ( $\left.{ }^{\star}\right)$. Photomicrographs were previously described in detail, and represent studies published in full in Welsh et al. (42). Similar results were described using recombinant human LTF (127). Sections were visualized at $100 \times$ magnification, stained with hematoxylin and eosin.

B cells into efficient antigen presenting cells (128). In another experimental model, LTF bound to monophosphoryl lipid A was shown to be equally effective in augmenting antibody response to bacteria as Freund's complete adjuvant (CFA) (129). Such a complex had negligible pro-inflammatory properties when compared with CFA, so a potential application of such an adjuvant would be conceivable in humans. Studies from our laboratory demonstrate that both bovine and human LTF added to the BCG vaccine led to increased protection in $\mathrm{C} 57 \mathrm{BL} / 6$ mice against subsequent challenge with virulent mycobacterial organisms, shown via decrease in bacterial burden in the primary lung and secondary disseminated organs, such as the spleen $(36,130-132)$. The C57BL/ 6 mice vaccinated with BCG and LTF had increased expression of IFN $\gamma$ mRNA within the lung soon postchallenge with virulent MTB, suggesting localization of increased $\mathrm{T}_{\mathrm{H}} 1$ responses at critical sites of clinical importance. The recall responses to heat-killed BCG in animals given the BCG LTF vaccine combination demonstrated increased levels of IFN- $\gamma$, in addition to other pro-inflammatory mediators, compared with the mice vaccinated only with BCG. IL- 4 and IL-10 were also reduced in the BCG LTF vaccinated groups (130). Lung histopathology showed significantly reduced pathological damage in mice immunized with BCG and LTF, where focal, lymphocytic, granulomas were seen surrounded by normal lung parenchyma. These enhanced pathological protective responses induced by the BCG LTF combination vaccine extend to $\mathrm{BALB} / \mathrm{c}$ mice, which typically demonstrate decreased $\mathrm{T}_{\mathrm{H}} 1$ responses to $\mathrm{MTB}$ compared with the more responsive C57BL/6 strain (133).

\section{Lactoferrin Inhibits Pathological Development during Autoimmune Disease}

Some time ago, we showed that New Zealand Black mice which had been treated for a prolonged period with bLTF exhibited a decreased frequency of positive Coombs' reactivity (134). Incubation of peritoneal cells with LTF resulted in decreased numbers of cells recognizing $\mathrm{Hb}$ erythrocyte hidden antigen on autologous erythrocytes. Since addition of $\mathrm{PGE}_{1}$ to the cultures of peritoneal exudate cells inhibited the number of $\mathrm{CD}^{+}$ autoantibody-producing B cells by $50 \%$ (135), the stimulation of COX1 expression by LTF (49) may well explain that protective effect of LTF. In another study, oral administration of LTF was examined for changes in experimental autoimmune encephalomyelitis (EAE) in Lewis rats (136). LTF treatment led to significant acceleration of recovery, taking into account the clinical score. In addition, there was highly elevated cell numbers in inguinal lymph nodes in the EAE rats which was normalized by the LTF treatments. Furthermore, LTF decreased the elevation of serum TNF- $\alpha$ and TGF $\beta$ concentrations. The histological analysis of the spinal cord revealed reduction in the number and size of inflammatory foci in LTF-treated rats. In addition, a small clinical trial on subjects suffering from multiple sclerosis (137) demonstrated that oral treatment of the patients with LTF resulted in a profound decrease of IFN $\gamma$ and increase of IL-10 secretion by whole blood cell cultures stimulated with cytokine inducers. These changes were accompanied with an improvement of their clinical status. The protective properties of LTF in the neurodegenerative diseases were in part explained by improving viability of Schwann cells (138). In addition, an immune deviation phenomenon may occur in this case as LTF was previously shown to preferentially inhibit antigen-specific proliferation and phenotype of $\mathrm{T}_{\mathrm{H}} 1$-type cell lines (139). Other studies have also concluded that skewing of adaptive T-cell function by LTF is a potential way to direct adaptive function $(125,133,140)$.

Other models identifying LTF to control pathological inflammation have been detailed, many of which have described directed changes on human clinical outcomes of disease states. Yin et al. revealed a profound hepatoprotective effect due to LTF 
within a mouse model of hepatitis induced via concanavalin A administration (141), which mimics the pathophysiology of human viral and autoimmune hepatitis. LTF had protective effects attributed to its inhibition of T-cell activation and production of IFN $\gamma$, as well as a noticed suppression of IL- 4 by hepatic natural killer T cells. The effects of human native LTF on experimental, caerulein-induced acute pancreatitis in rats were also studied (142). LTF significantly reduced elevation of serum amylase, and of pancreatic wet weight. Histologic alterations within the pancreas were also greatly suppressed. In addition, LTF exhibited regulatory effects on bone cell activity (143), and a profound, regenerative effect on bone structure in ovariectomized rats
(144). Also, a protective effect of LTF against acute acid refluxinduced esophageal damage was demonstrated in rats (145). A selected list of LTF protective actions in various pathological states is presented in Table 2.

Lastly, it is worth mentioning the adjunct effect of LTF in treatment of certain infections with antibiotics (149-152). The utility of LTF to control bacterial and viral growth (153-155), and onset of subsequent inflammation and tissue damage, contributes greatly to its general effects to control development of SIRS and septic pathology $(16,156)$. This phenomena, and similar interactions of LTF with pathogenic organisms, have been well documented in multiple excellent separate reviews $(43,46)$.

TABLE 2 | Selected examples of lactoferrin (LTF) protective activity against defined inflammation-induced pathologies.

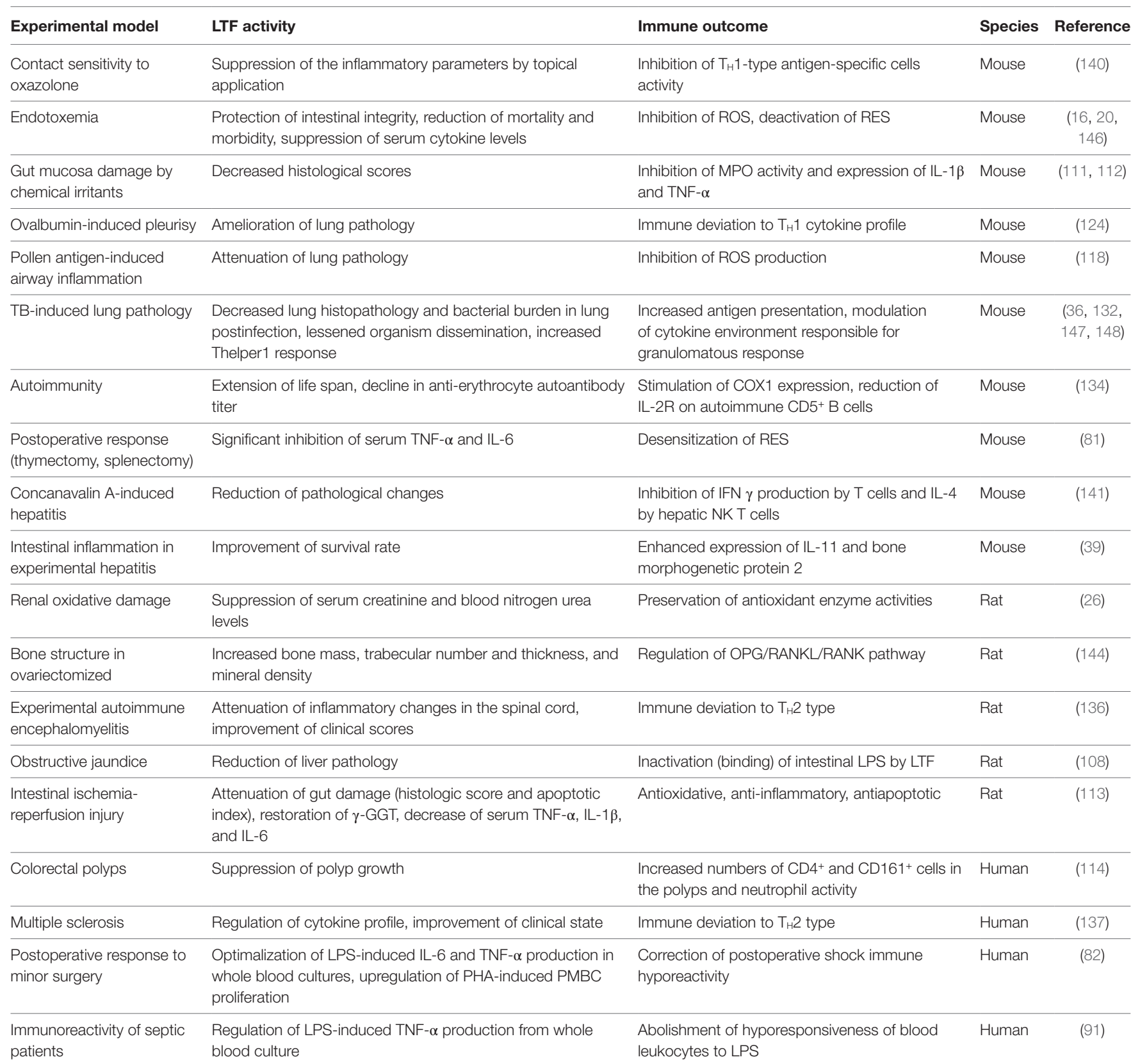




\section{CONCLUSION}

In conclusion, LTF plays a major functional role in physiologic homeostasis as related to development of disease and associated pathology. In many cases, LTF fulfills its anti-inflammatory roles via different cell receptors and activation of various cell signaling pathways, often through iron-dependent mechanisms. In fact, the ability of LTF to both sequester iron and to direct reactive oxygen intermediates is a major factor in lessening damage due to excessive inflammatory responses. The immunomodulatory nature of this protein derives from its unique ability to sense the immune activation status of an organism and act accordingly. The interaction of LTF with its receptors can trigger "redundant" protective effects as reflected by (1) regulation of enzyme activities and ROS production; (2) immune deviation and modulation;

\section{REFERENCES}

1. Actor JK, Hwang SA, Kruzel ML. Lactoferrin as a natural immune modulator. Curr Pharm Des (2009) 15:1956-73. doi:10.2174/138161209788453202

2. Kruzel ML, Actor JK, Boldogh I, Zimecki M. Lactoferrin in health and disease. Postepy Hig Med Dosw (2007) 61:261-7.

3. Baker EN, Anderson BF, Baker HM, Day CL, Haridas M, Norris GE, et al. Three-dimensional structure of lactoferrin in various functional states. $A d v$ Exp Med Biol (1994) 357:1-12. doi:10.1007/978-1-4615-2548-6_1

4. Kruzel ML, Zimecki M. Lactoferrin and immunologic dissonance: clinical implications. Arch Immunol Ther Exp (2002) 50:399-410.

5. Samyn-Petit B, Wajda Dubos JP, Chirat F, Coddeville B, Demaizieres G, Farrer S, et al. Comparative analysis of the site-specific N-glycosylation of human lactoferrin produced in maize and tobacco plants. Eur J Biochem (2003) 270:3235-42. doi:10.1046/j.1432-1033.2003.03706.x

6. Karav S, German JB, Rouquie C, Le Parc A, Barile D. Studying lactoferrin N-glycosylation. Int J Mol Sci (2017) 18(4):870. doi:10.3390/ijms18040870

7. Choi BK, Actor JK, Rios S, d’Anjou M, Stadheim TA, Warburton S, et al. Recombinant human lactoferrin expressed in glycoengineered Pichia pastoris: effect of terminal $\mathrm{N}$-acetylneuraminic acid on in vitro secondary humoral immune response. Glycoconj J (2008) 25:581-93. doi:10.1007/ s10719-008-9123-y

8. Zimecki M, Artym J, Kocieba M, Duk M, Kruzel ML. The effect of carbohydrate moiety structure on the immunoregulatory activity of lactoferrin in vitro. Cell Mol Biol Lett (2014) 19:284-96. doi:10.2478/s11658-014-0196-2

9. Zimecki M, Artym J, Kocieba M, Kaleta-Kuratewicz K, Kuropka P, Kuryszko J, et al. Homologous lactoferrin triggers mobilization of the myelocytic lineage of bone marrow in experimental mice. Stem Cells Dev (2013) 22:3261-70. doi:10.1089/scd.2013.0242

10. Francis N, Wong SH, Hampson P, Wang K, Young SP, Deigner HP, et al. Lactoferrin inhibits neutrophil apoptosis via blockade of proximal apoptotic signaling events. Biochim Biophys Acta (2011) 1813:1822-6. doi:10.1016/j. bbamcr.2011.07.004

11. Okubo K, Kamiya M, Urano Y, Nishi H, Herter JM, Mayadas T, et al. Lactoferrin suppresses neutrophil extracellular traps release in inflammation. EBioMedicine (2016) 10:204-15. doi:10.1016/j.ebiom.2016.07.012

12. Lonnerdal B, Iyer S. Lactoferrin: molecular structure and biological function. Annu Rev Nutr (1995) 15:93-110. doi:10.1146/annurev.nu.15.070195.000521

13. Sanchez L, Calvo M, Brock JH. Biological role of lactoferrin. Arch Dis Child (1992) 67:657-61. doi:10.1136/adc.67.5.657

14. Baveye S, Elass E, Mazurier J, Spik G, Legrand D. Lactoferrin: a multifunctional glycoprotein involved in the modulation of the inflammatory process. Clin Chem Lab Med (1999) 37:281-6. doi:10.1515/CCLM.1999.049

15. Baynes RD, Bezwoda WR. Lactoferrin and the inflammatory response. $A d v$ Exp Med Biol (1994) 357:133-41. doi:10.1007/978-1-4615-2548-6_13

16. Kruzel ML, Harari Y, Mailman D, Actor JK, Zimecki M. Differential effects of prophylactic, concurrent and therapeutic lactoferrin treatment on LPS-induced inflammatory responses in mice. Clin Exp Immunol (2002) 130:25-31. doi:10.1046/j.1365-2249.2002.01956.x
(3) change of cell phenotype and cytokine profile; (4) binding to LPS or competition with its receptors, and (5) prevention of cell apoptosis. Many additional immune pathways are also affected, which culminate in the consequence of attenuated pathological changes as tissue repair processes are initiated.

\section{AUTHOR CONTRIBUTIONS}

$\mathrm{MK}, \mathrm{MZ}$, and JA contributed equally to the writing of the manuscript.

\section{FUNDING}

This work was supported by NIH grants 2R42-AI117990-02 and 2R42NS090650-02.

17. Manzoni P, Decembrino L, Stolfi I, Pugni L, Rinaldi M, Cattani S, et al. Lactoferrin and prevention of late-onset sepsis in the pre-term neonates. Early Hum Dev (2010) 86(Suppl 1):59-61. doi:10.1016/j.earlhumdev.2010.01.009

18. Manzoni P, Rinaldi M, Cattani S, Pugni L, Romeo MG, Messner H, et al. Bovine lactoferrin supplementation for prevention of late-onset sepsis in very low-birth-weight neonates: a randomized trial. JAMA (2009) 302:1421-8. doi:10.1001/jama.2009.1403

19. Ochoa TJ, Zegarra J, Cam L, Llanos R, Pezo A, Cruz K, et al. Randomized controlled trial of lactoferrin for prevention of sepsis in peruvian neonates less than 2500 g. Pediatr Infect Dis J (2015) 34:571-6. doi:10.1097/ INF.0000000000000593

20. Kruzel ML, Harari Y, Chen CY, Castro GA. Lactoferrin protects gut mucosal integrity during endotoxemia induced by lipopolysaccharide in mice. Inflammation (2000) 24:33-44. doi:10.1023/A:1006935908960

21. Ochoa TJ, Chea-Woo E, Baiocchi N, Pecho I, Campos M, Prada A, et al. Randomized double-blind controlled trial of bovine lactoferrin for prevention of diarrhea in children. J Pediatr (2013) 162:349-56. doi:10.1016/j. jpeds.2012.07.043

22. Ochoa TJ, Pezo A, Cruz K, Chea-Woo E, Cleary TG. Clinical studies of lactoferrin in children. Biochem Cell Biol (2012) 90:457-67. doi:10.1139/o11-087

23. Fine DH, Toruner GA, Velliyagounder K, Sampathkumar V, Godboley D, Furgang D. A lactotransferrin single nucleotide polymorphism demonstrates biological activity that can reduce susceptibility to caries. Infect Immun (2013) 81:1596-605. doi:10.1128/IAI.01063-12

24. MohamedJA,DuPontHL,JiangZD,Belkind-GersonJ, FigueroaJF,ArmitigeLY, et al. A novel single-nucleotide polymorphism in the lactoferrin gene is associated with susceptibility to diarrhea in North American travelers to Mexico. Clin Infect Dis (2007) 44:945-52. doi:10.1086/512199

25. Elass-Rochard E, Legrand D, Salmon V, Roseanu A, Trif M, Tobias PS, et al. Lactoferrin inhibits the endotoxin interaction with CD14 by competition with the lipopolysaccharide-binding protein. Infect Immun (1998) 66:486-91.

26. Okazaki Y, Kono I, Kuriki T, Funahashi S, Fushimi S, Iqbal M, et al. Bovine lactoferrin ameliorates ferric nitrilotriacetate-induced renal oxidative damage in rats. J Clin Biochem Nutr (2012) 51:84-90. doi:10.3164/jcbn.11-100

27. Baynes R, Bezwoda W, Bothwell T, Khan Q, Mansoor N. The non-immune inflammatory response: serial changes in plasma iron, iron-binding capacity, lactoferrin, ferritin and C-reactive protein. Scand J Clin Lab Invest (1986) 46:695-704. doi:10.3109/00365518609083733

28. de la Rosa G, Yang D, Tewary P, Varadhachary A, Oppenheim JJ. Lactoferrin acts as an alarmin to promote the recruitment and activation of APCs and antigen-specific immune responses. J Immunol (2008) 180:6868-76. doi:10.4049/jimmunol.180.10.6868

29. Oppenheim JJ, Tewary P, de la Rosa G, Yang D. Alarmins initiate host defense. Adv Exp Med Biol (2007) 601:185-94. doi:10.1007/978-0-387-72005-0_19

30. Yang D, de la Rosa G, Tewary P, Oppenheim JJ. Alarmins link neutrophils and dendritic cells. Trends Immunol (2009) 30:531-7. doi:10.1016/j.it.2009.07.004

31. Hwang SA, Wilk KM, Bangale YA, Kruzel ML, Actor JK. Lactoferrin modulation of IL-12 and IL-10 response from activated murine leukocytes. Med Microbiol Immunol (2007) 196:171-80. doi:10.1007/s00430-007-0041-6 
32. Zimecki M, Artym J, Chodaczek G, Kocieba M, Kuryszko J, Houszka M, et al. Immunoregulatory function of lactoferrin in immunosuppressed and autoimmune animals. Postepy Hig Med Dosw (2007) 61:283-7.

33. Zimecki M, Kruzel ML. Milk-derived proteins and peptides of potential therapeutic and nutritive value. J Exp Ther Oncol (2007) 6:89-106.

34. Zimecki M, Mazurier J, Spik G, Kapp JA. Human lactoferrin induces phenotypic and functional changes in murine splenic B cells. Immunology (1995) $86: 122-7$.

35. Zimecki M, Miedzybrodzki R, Mazurier J, Spik G. Regulatory effects of lactoferrin and lipopolysaccharide on LFA-1 expression on human peripheral blood mononuclear cells. Arch Immunol Ther Exp (1999) 47:257-64.

36. Hwang SA, Kruzel ML, Actor JK. Lactoferrin augments BCG vaccine efficacy to generate $\mathrm{T}$ helper response and subsequent protection against challenge with virulent Mycobacterium tuberculosis. Int Immunopharmacol (2005) 5:591-9. doi:10.1016/j.intimp.2004.11.006

37. Artym J, Zimecki M, Kruzel ML. Effect of lactoferrin on the methotrexate-induced suppression of the cellular and humoral immune response in mice. Anticancer Res (2004) 24:3831-6.

38. KruzelML,BacsiA,ChoudhuryB,SurS,BoldoghI.Lactoferrindecreasespollen antigen-induced allergic airway inflammation in a murine model of asthma. Immunology (2006) 119:159-66. doi:10.1111/j.1365-2567.2006.02417.x

39. Kuhara T, Tanaka A, Yamauchi K, Iwatsuki K. Bovine lactoferrin ingestion protects against inflammation via IL-11 induction in the small intestine of mice with hepatitis. Br JNutr (2014) 111:1801-10. doi:10.1017/ S0007114513004315

40. Togawa J, Nagase H, Tanaka K, Inamori M, Nakajima A, Ueno N, et al. Oral administration of lactoferrin reduces colitis in rats via modulation of the immune system and correction of cytokine imbalance. J Gastroenterol Hepatol (2002) 17:1291-8. doi:10.1046/j.1440-1746.2002.02868.x

41. Welsh KJ, Hwang SA, Boyd S, Kruzel ML, Hunter RL, Actor JK. Influence of oral lactoferrin on Mycobacterium tuberculosis induced immunopathology. Tuberculosis (2011) 91(Suppl 1):S105-13. doi:10.1016/j.tube.2011.10.019

42. Welsh KJ, Hwang SA, Hunter RL, Kruzel ML, Actor JK. Lactoferrin modulation of mycobacterial cord factor trehalose 6-6'-dimycolate induced granulomatous response. Transl Res (2010) 156:207-15. doi:10.1016/j. trsl.2010.06.001

43. Vogel HJ. Lactoferrin, a bird's eye view. Biochem Cell Biol (2012) 90:233-44. doi:10.1139/o2012-016

44. Legrand D. Overview of lactoferrin as a natural immune modulator. J Pediatr (2016) 173(Suppl):S10-5. doi:10.1016/j.jpeds.2016.02.071

45. Baker EN, Baker HM. A structural framework for understanding the multifunctional character of lactoferrin. Biochimie (2009) 91:3-10. doi:10.1016/j. biochi.2008.05.006

46. Legrand D, Pierce A, Elass E, Carpentier M, Mariller C, Mazurier J. Lactoferrin structure and functions. Adv Exp Med Biol (2008) 606:163-94. doi:10.1007/978-0-387-74087-4_6

47. Puddu P, Valenti P, Gessani S. Immunomodulatory effects of lactoferrin on antigen presenting cells. Biochimie (2009) 91:11-8. doi:10.1016/j. biochi.2008.05.005

48. Legrand D, Elass E, Carpentier M, Mazurier J. Interactions of lactoferrin with cells involved in immune function. Biochem Cell Biol (2006) 84:282-90. doi:10.1139/o06-045

49. Mayeur S, Spahis S, Pouliot Y, Levy E. Lactoferrin, a pleiotropic protein in health and disease. Antioxid Redox Signal (2016) 24:813-36. doi:10.1089/ ars.2015.6458

50. Chen GY, Nunez G. Sterile inflammation: sensing and reacting to damage. Nat Rev Immunol (2010) 10:826-37. doi:10.1038/nri2873

51. Markiewski MM, Lambris JD. The role of complement in inflammatory diseases from behind the scenes into the spotlight. Am J Pathol (2007) 171:715-27. doi:10.2353/ajpath.2007.070166

52. Calame DG, Mueller-Ortiz SL, Wetsel RA. Innate and adaptive immunologic functions of complement in the host response to Listeria monocytogenes infection. Immunobiology (2016) 221:1407-17. doi:10.1016/j.imbio.2016.07.004

53. McDonald B, Pittman K, Menezes GB, Hirota SA, Slaba I, Waterhouse CC, et al. Intravascular danger signals guide neutrophils to sites of sterile inflammation. Science (2010) 330:362-6. doi:10.1126/science.1195491

54. Sangiuliano B, Perez NM, Moreira DF, Belizario JE. Cell death-associated molecular-pattern molecules: inflammatory signaling and control. Mediators Inflamm (2014) 2014:821043. doi:10.1155/2014/821043
55. He Y, Lawlor NT, Newburg DS. Human milk components modulate toll-like receptor-mediated inflammation. Adv Nutr (2016) 7:102-11. doi:10.3945/ an. 115.010090

56. Legrand D, Mazurier J. A critical review of the roles of host lactoferrin in immunity. Biometals (2010) 23:365-76. doi:10.1007/s10534-010-9297-1

57. Curran CS, Demick KP, Mansfield JM. Lactoferrin activates macrophages via TLR4-dependent and -independent signaling pathways. Cell Immunol (2006) 242:23-30. doi:10.1016/j.cellimm.2006.08.006

58. Drago-Serrano ME, de la Garza-Amaya M, Luna JS, Campos-Rodriguez R. Lactoferrin-lipopolysaccharide (LPS) binding as key to antibacterial and antiendotoxic effects. Int Immunopharmacol (2012) 12:1-9. doi:10.1016/j. intimp.2011.11.002

59. Zheng Y, Qin Z, Ye Q, Chen P, Wang Z, Yan Q, et al. Lactoferrin suppresses the Epstein-Barr virus-induced inflammatory response by interfering with pattern recognition of TLR2 and TLR9. Lab Invest (2014) 94:1188-99. doi:10.1038/labinvest.2014.105

60. Huang Q, Liu D, Majewski P, Schulte LC, Korn JM, Young RA, et al. The plasticity of dendritic cell responses to pathogens and their components. Science (2001) 294:870-5. doi:10.1126/science.294.5543.870

61. Zemankova N, Chlebova K, Matiasovic J, Prodelalova J, Gebauer J, Faldyna M. Bovine lactoferrin free of lipopolysaccharide can induce a proinflammatory response of macrophages. BMC Vet Res (2016) 12:251. doi:10.1186/ s12917-016-0878-2

62. Vallabhapurapu S, Karin M. Regulation and function of NF-kappaB transcription factors in the immune system. Annu Rev Immunol (2009) 27:693-733. doi:10.1146/annurev.immunol.021908.132641

63. Rainard P. Activation of the classical pathway of complement by binding of bovine lactoferrin to unencapsulated Streptococcus agalactiae. Immunology (1993) 79:648-52.

64. Kievits F, Kijlstra A. Inhibition of C3 deposition on solid-phase bound immune complexes by lactoferrin. Immunology (1985) 54:449-56.

65. Samuelsen O, Haukland HH, Ulvatne H, Vorland LH. Anti-complement effects of lactoferrin-derived peptides. FEMS Immunol Med Microbiol (2004) 41:141-8. doi:10.1016/j.femsim.2004.02.006

66. Lopez-Boado YS, Espinola M, Bahr S, Belaaouaj A. Neutrophil serine proteinases cleave bacterial flagellin, abrogating its host response-inducing activity. J Immunol (2004) 172:509-15. doi:10.4049/jimmunol.172.1.509

67. Eipper S, Steiner R, Lesner A, Sienczyk M, Palesch D, Halatsch ME, et al. Lactoferrin is an allosteric enhancer of the proteolytic activity of cathepsin G. PLoS One (2016) 11:e0151509. doi:10.1371/journal.pone.0151509

68. Cutone A, Rosa L, Lepanto MS, Scotti MJ, Berlutti F, Bonaccorsi di Patti MC, et al. Lactoferrin efficiently counteracts the inflammation-induced changes of the iron homeostasis system in macrophages. Front Immunol (2017) 8:705. doi:10.3389/fimmu.2017.00705

69. Zimecki M, Kocieba M, Kruzel M. Immunoregulatory activities of lactoferrin in the delayed type hypersensitivity in mice are mediated by a receptor with affinity to mannose. Immunobiology (2002) 205:120-31. doi:10.1078/0171-2985-00115

70. Kruzel ML, Actor JK, Zimecki M, Wise J, Ploszaj P, Mirza S, et al. Novel recombinant human lactoferrin: differential activation of oxidative stress related gene expression. J Biotechnol (2013) 168:666-75. doi:10.1016/j. jbiotec.2013.09.011

71. Marnett LJ. Oxyradicals and DNA damage. Carcinogenesis (2000) 21:361-70. doi:10.1093/carcin/21.3.361

72. Misonou H, Morishima-Kawashima M, Ihara Y. Oxidative stress induces intracellular accumulation of amyloid beta-protein (Abeta) in human neuroblastoma cells. Biochemistry (2000) 39:6951-9. doi:10.1021/bi000169p

73. Ruef J, Peter K, Nordt TK, Runge MS, Kubler W, Bode C. Oxidative stress and atherosclerosis: its relationship to growth factors, thrombus formation and therapeutic approaches. Thromb Haemost (1999) 82(Suppl 1):32-7.

74. Poli G, Schaur RJ. 4-Hydroxynonenal in the pathomechanisms of oxidative stress. IUBMB Life (2000) 50:315-21. doi:10.1080/713803726

75. Kruzel ML, Actor JK, Radak Z, Bacsi A, Saavedra-Molina A, Boldogh I. Lactoferrin decreases LPS-induced mitochondrial dysfunction in cultured cells and in animal endotoxemia model. Innate Immun (2010) 16:67-79. doi:10.1177/1753425909105317

76. Zhang AS, Enns CA. Iron homeostasis: recently identified proteins provide insight into novel control mechanisms. JBiol Chem (2009) 284:711-5. doi:10.1074/jbc.R800017200 
77. Zimecki M, Wieczorek Z, Kapp JA, Pierce CW. Structures on T cells and macrophages involved in interleukin 1 (Il-1) secretion by macrophages upon contact with syngeneic thymocytes. Arch Immunol Ther Exp (1989) 37:587-92.

78. Zupin L, Angelelli F, Grasso DL, Crovella S. Lactoferrin gene polymorphisms in Italian patients with recurrent tonsillitis. Int J Pediatr Otorhinolaryngol (2016) 88:153-6. doi:10.1016/j.ijporl.2016.07.002

79. Fine DH. Lactoferrin: a roadmap to the borderland between caries and periodontal disease. J Dent Res (2015) 94:768-76. doi:10.1177/0022034515577413

80. Barber MF, Kronenberg Z, Yandell M, Elde NC. Antimicrobial functions of lactoferrin promote genetic conflicts in ancient primates and modern humans. PLoS Genet (2016) 12:e1006063. doi:10.1371/journal.pgen.1006063

81. Zimecki M, Wlaszczyk A, Zagulski T, Kubler A. Lactoferrin lowers serum interleukin 6 and tumor necrosis factor alpha levels in mice subjected to surgery. Arch Immunol Ther Exp (1998) 46:97-104.

82. Zimecki M, Wlaszczyk A, Wojciechowski R, Dawiskiba J, Kruzel M. Lactoferrin regulates the immune responses in post-surgical patients. Arch Immunol Ther Exp (2001) 49:325-33.

83. Puddu P, Latorre D, Carollo M, Catizone A, Ricci G, Valenti P, et al. Bovine lactoferrin counteracts Toll-like receptor mediated activation signals in antigen presenting cells. PLoS One (2011) 6:e22504. doi:10.1371/journal. pone.0022504

84. Tang L, Wu JJ, Ma Q, Cui T, Andreopoulos FM, Gil J, et al. Human lactoferrin stimulates skin keratinocyte function and wound re-epithelialization. $\mathrm{Br}$ J Dermatol (2010) 163:38-47. doi:10.1111/j.1365-2133.2010.09748.x

85. Uehara A, Sugawara Y, Kurata S, Fujimoto Y, Fukase K, Kusumoto S, et al. Chemically synthesized pathogen-associated molecular patterns increase the expression of peptidoglycan recognition proteins via toll-like receptors, NOD1 and NOD2 in human oral epithelial cells. Cell Microbiol (2005) 7:675-86. doi:10.1111/j.1462-5822.2004.00500.x

86. Spadaro M, Montone M, Arigoni M, Cantarella D, Forni G, Pericle F, et al. Recombinant human lactoferrin induces human and mouse dendritic cell maturation via Toll-like receptors 2 and 4. FASEB J (2014) 28:416-29. doi:10.1096/fj.13-229591

87. Novak N, Allam JP. Mucosal dendritic cells in allergy and immunotherapy. Allergy (2011) 66(Suppl 95):22-4. doi:10.1111/j.1398-9995.2011.02626.x

88. Cario E, Rosenberg IM, Brandwein SL, Beck PL, Reinecker HC, Podolsky DK. Lipopolysaccharide activates distinct signaling pathways in intestinal epithelial cell lines expressing toll-like receptors. J Immunol (2000) 164:966-72. doi:10.4049/jimmunol.164.2.966

89. Hayashi T, To M, Saruta J, Sato C, Yamamoto Y, Kondo Y, et al. Salivary lactoferrin is transferred into the brain via the sublingual route. Biosci Biotechnol Biochem (2017) 81:1300-4. doi:10.1080/09168451.2017.1308241

90. Ginet V, van de Looij Y, Petrenko V, Toulotte A, Kiss J, Huppi PS, et al. Lactoferrin during lactation reduces lipopolysaccharide-induced brain injury. Biofactors (2016) 42:323-36. doi:10.1002/biof.1278

91. Artym J, Kocieba M, Zaczyńska E, Adamik B, Kubler A, Zimecki M, et al. Immunomodulatory properties of human recombinant lactoferrin in mice and their implications for therapeutic use in humans. Int Immunopharmacol (2014) 20(1):157-63. doi:10.1016/j.intimp.2014.02.029

92. Wang $\mathrm{H}, \mathrm{Ma} \mathrm{S}$. The cytokine storm and factors determining the sequence and severity of organ dysfunction in multiple organ dysfunction syndrome. Am J Emerg Med (2008) 26:711-5. doi:10.1016/j.ajem.2007.10.031

93. Oviedo-Boyso J, Bravo-Patino A, Baizabal-Aguirre VM. Collaborative action of Toll-like and NOD-like receptors as modulators of the inflammatory response to pathogenic bacteria. Mediators Inflamm (2014) 2014:432785. doi: $10.1155 / 2014 / 432785$

94. Exline MC, Crouser ED. Mitochondrial mechanisms of sepsis-induced organ failure. Front Biosci (2008) 13:5030-41.

95. Shapiro L, Gelfand JA. Cytokines and sepsis: pathophysiology and therapy. New Horiz (1993) 1:13-22.

96. Van Amersfoort ES, Van Berkel TJ, Kuiper J. Receptors, mediators, and mechanisms involved in bacterial sepsis and septic shock. Clin Microbiol Rev (2003) 16:379-414. doi:10.1128/CMR.16.3.379-414.2003

97. Deitch EA. Multiple organ failure. Pathophysiology and potential future therapy. Ann Surg (1992) 216:117-34. doi:10.1097/00000658-199208000-00002

98. Deitch EA. Role of bacterial translocation in necrotizing enterocolitis. Acta Paediatr (1994) 396:33-6. doi:10.1111/j.1651-2227.1994.tb13239.x
99. Nadler EP, Upperman JS, Dickinson EC, Ford HR. Nitric oxide and intestinal barrier failure. Semin Pediatr Surg (1999) 8:148-54. doi:10.1016/ S1055-8586(99)70016-8

100. DeMaria EJ, Dalton J. Bacterial translocation and the release of endotoxin and cytokines following trauma. In: Sugerman HJ, DeMaria EJ, editors. Cytokines in Trauma and Hemorrhage. Portland, OR: Chapman \& Hall (1997). p. 43-61.

101. Zagulski T, Lipinski P, Zagulska A, Broniek S, Jarzabek Z. Lactoferrin can protect mice against a lethal dose of Escherichia coli in experimental infection in vivo. Br J Exp Pathol (1989) 70:697-704.

102. Godinez-Victoria M, Cruz-Hernandez TR, Reyna-Garfias H, BarbosaCabrera RE, Drago-Serrano ME, Sanchez-Gomez MC, et al. Modulation by bovine lactoferrin of parameters associated with the IgA response in the proximal and distal small intestine of BALB/c mice. Immunopharmacol Immunotoxicol (2017) 39:66-73. doi:10.1080/08923973.2017.1282513

103. Doursout MF, Horton H, Hoang L, Liang Y, Hwang SA, Boyd S, et al. Lactoferrin moderates LPS-induced hypotensive response and gut injury in rats. Int Immunopharmacol (2013) 15:227-31. doi:10.1016/j. intimp.2012.12.009

104. Artym J, Zimecki M, Kruzel ML. Enhanced clearance of Escherichia coli and Staphylococcus aureus in mice treated with cyclophosphamide and lactoferrin. Int Immunopharmacol (2004) 4:1149-57. doi:10.1016/j.intimp.2004.05.002

105. Zimecki M, Artym J, Chodaczek G, Kocieba M, Kruzel ML. Protective effects of lactoferrin in Escherichia coli-induced bacteremia in mice: relationship to reduced serum TNF alpha level and increased turnover of neutrophils. Inflamm Res (2004) 53:292-6. doi:10.1007/s00011-004-1257-1

106. Zimecki M, Chodaczek G, Kocieba M, Kruzel ML. Lethality in LPS-induced endotoxemia in $\mathrm{C} 3 \mathrm{H} / \mathrm{HeCr}$ mice is associated with prevalence of proinflammatory cytokines: lack of protective action of lactoferrin. FEMS Immunol Med Microbiol (2004) 42:167-72. doi:10.1016/j.femsim.2004.04.003

107. Scott-Conner CE, Grogan JB. The pathophysiology of biliary obstruction and its effect on phagocytic and immune function. J Surg Res (1994) 57:316-36. doi:10.1006/jsre.1994.1151

108. Zimecki M, Dawiskiba J, Zawirska B, Krawczyk Z, Kruzel M. Bovine lactoferrin decreases histopathological changes in the liver and regulates cytokine production by splenocytes of obstructive jaundiced rats. Inflamm Res (2003) 52:305-10. doi:10.1007/s00011-003-1178-4

109. Pena-Juarez MC, Campos-Rodriguez R, Godinez-Victoria M, CruzHernandez TR, Reyna-Garfias H, Barbosa-Cabrera RE, et al. Effect of bovine lactoferrin treatment followed by acute stress on the IgA-response in small intestine of BALB/c mice. Immunol Invest (2016) 45:652-67. doi:10.1080/ 08820139.2016.1202959

110. Togawa J, Nagase H, Tanaka K, Inamori M, Umezawa T, Nakajima A, et al. Lactoferrin reduces colitis in rats via modulation of the immune system and correction of cytokine imbalance. Am J Physiol Gastrointest Liver Physiol (2002) 283:G187-95. doi:10.1152/ajpgi.00331.2001

111. Li L, Ren F, Yun Z, An Y, Wang C, Yan X. Determination of the effects of lactoferrin in a preclinical mouse model of experimental colitis. Mol Med Rep (2013) 8:1125-9. doi:10.3892/mmr.2013.1632

112. MacManus CF, Collins CB, Nguyen TT, Alfano RW, Jedlicka P, de Zoeten EF. VEN-120, a recombinant human lactoferrin, promotes a regulatory $\mathrm{T}$ cell (Treg) phenotype and drives resolution of inflammation in distinct murine models of inflammatory bowel disease. J Crohns Colitis (2017) 11(9):1101-12. doi:10.1093/ecco-jcc/jjx056

113. Zhang T, Wang Y, Ban R, Tong L, Qiao H, Lao H, et al. Oral administration of lactoferrin attenuates intestinal ischemia-reperfusion injury in rats. Eur Surg Res (2012) 49:99-106. doi:10.1159/000342633

114. Iigo M, Alexander DB, Xu J, Futakuchi M, Suzui M, Kozu T, et al. Inhibition of intestinal polyp growth by oral ingestion of bovine lactoferrin and immune cells in the large intestine. Biometals (2014) 27:1017-29. doi:10.1007/ s10534-014-9747-2

115. Hensley K, Robinson KA, Gabbita SP, Salsman S, Floyd RA. Reactive oxygen species, cell signaling, and cell injury. Free Radic Biol Med (2000) 28:1456-62. doi:10.1016/S0891-5849(00)00252-5

116. Holgate ST. The epidemic of allergy and asthma. Nature (1999) 402:B2-4. doi: $10.1038 / 35037000$

117. Bacsi A, Dharajiya N, Choudhury BK, Sur S, Boldogh I. Effect of pollen-mediated oxidative stress on immediate hypersensitivity reactions and 
late-phase inflammation in allergic conjunctivitis. J Allergy Clin Immunol (2005) 116:836-43. doi:10.1016/j.jaci.2005.06.002

118. Boldogh I, Bacsi A, Choudhury BK, Dharajiya N, Alam R, Hazra TK, et al. ROS generated by pollen NADPH oxidase provide a signal that augments antigen-induced allergic airway inflammation. J Clin Invest (2005) 115:216979. doi:10.1172/JCI24422

119. Brand MD, Affourtit C, Esteves TC, Green K, Lambert AJ, Miwa S, et al. Mitochondrial superoxide: production, biological effects, and activation of uncoupling proteins. Free Radic Biol Med (2004) 37:755-67. doi:10.1016/j. freeradbiomed.2004.05.034

120. Gutteridge JM, Mumby S, Quinlan GJ, Chung KF, Evans TW. Pro-oxidant iron is present in human pulmonary epithelial lining fluid: implications for oxidative stress in the lung. Biochem Biophys Res Commun (1996) 220:1024-7. doi:10.1006/bbrc. 1996.0518

121. Mateos F, Brock JH, Perez-Arellano JL. Iron metabolism in the lower respiratory tract. Thorax (1998) 53:594-600. doi:10.1136/thx.53.7.594

122. Park YY, Hybertson BM, Wright RM, Repine JE. Serum ferritin increases in hemorrhaged rats that develop acute lung injury: effect of an iron-deficient diet. Inflammation (2003) 27:257-63. doi:10.1023/A:1025044732423

123. Zhao GI, Ayene S, Fisher AB. Role of iron in ischemia-reperfusion oxidative injury of rat lungs. Am J Respir Cell Mol Biol (1997) 16:293-9. doi:10.1165/ ajrcmb.16.3.9070614

124. Zimecki M, Artym J, Kocieba M, Kaleta-Kuratewicz K, Kruzel ML. Lactoferrin restrains allergen-induced pleurisy in mice. Inflamm Res (2012) 61:1247-55. doi:10.1007/s00011-012-0522-y

125. Wang SB, Deng YQ, Ren J, Xiao BK, Chen Z, Tao ZZ. Lactoferrin administration into the nostril alleviates murine allergic rhinitis and its mechanisms. Scand J Immunol (2013) 78:507-15. doi:10.1111/sji.12118

126. Bournazou I, Mackenzie KJ, Duffin R, Rossi AG, Gregory CD. Inhibition of eosinophil migration by lactoferrin. Immunol Cell Biol (2010) 88:220-3. doi:10.1038/icb.2009.86

127. Actor JK. Lactoferrin: a modulator for immunity against tuberculosis related granulomatous pathology. Mediators Inflamm (2015) 2015:409596. doi:10.1155/2015/409596

128. Zimecki M, Mazurier J, Machnicki M, Wieczorek Z, Montreuil J, Spik G. Immunostimulatory activity of lactotransferrin and maturation of CD4CD8- murine thymocytes. Immunol Lett (1991) 30:119-23. doi:10.1016/ 0165-2478(91)90099-V

129. Chodaczek G, Zimecki M, Lukasiewicz J, Lugowski C. A complex of lactoferrin with monophosphoryl lipid A is an efficient adjuvant of the humoral and cellular immune response in mice. Med Microbiol Immunol (2006) 195:207-16. doi:10.1007/s00430-006-0020-3

130. Hwang SA, Welsh KJ, Boyd S, Kruzel ML, Actor JK. Comparing efficacy of BCG/lactoferrin primary vaccination versus booster regimen. Tuberculosis (2011) 91(Suppl 1):S90-5. doi:10.1016/j.tube.2011.10.017

131. Hwang SA, Welsh KJ, Kruzel ML, Actor JK. Lactoferrin augmentation of the BCG vaccine leads to increased pulmonary integrity. Tuberc Res Treat (2011) 2011:835410. doi:10.1155/2011/835410

132. Hwang SA, Wilk K, Kruzel ML, Actor JK. A novel recombinant human lactoferrin augments the BCG vaccine and protects alveolar integrity upon infection with Mycobacterium tuberculosis in mice. Vaccine (2009) 27:3026-34. doi:10.1016/j.vaccine.2009.03.036

133. Hwang SA, Arora R, Kruzel ML, Actor JK. Lactoferrin enhances efficacy of the BCG vaccine: comparison between two inbred mice strains (C57BL/6 and BALB/c). Tuberculosis (2009) 89(Suppl 1):S49-54. doi:10.1016/ S1472-9792(09)70012-5

134. Zimecki M, Wieczorek Z, Mazurier J, Spik G. Lactoferrin lowers the incidence of positive Coombs' test in New Zealand black mice. Arch Immunol Ther $\operatorname{Exp}$ (1995) 43:207-9.

135. Zimecki M, Webb DR Jr. The role of prostaglandins in the control of the immune response to an autologous red blood cell antigen (Hb). Clin Immunol Immunopathol (1977) 8:420-9. doi:10.1016/0090-1229(77) 90006-X

136. Zimecki M, Kocieba M, Chodaczek G, Houszka M, Kruzel ML. Lactoferrin ameliorates symptoms of experimental encephalomyelitis in Lewis rats. J Neuroimmunol (2007) 182:160-6. doi:10.1016/j.jneuroim.2006.10.008

137. Kruzel M, Artym J, Chodaczek G, Kocieba M, Kochanowska I, Kruzel T, et al. Effects of lactoferrin on stress-related immune dysfunction in mice and humans. Proceedings of the 4th International Whey Conference; Chicago, IL, USA. (2005). p. 121-32.
138. Lin TY, Kuo CD. Bovine lactoferrin protects RSC96 Schwann cells from tumor necrosis factor-alpha-induced growth arrest via extracellular-signal-regulated kinase 1/2. Neuroscience (2008) 151:396-402. doi:10.1016/j. neuroscience.2007.10.018

139. Zimecki M, Mazurier J, Spik G, Kapp JA. Lactoferrin inhibits proliferative response and cytokine production of TH1 but not TH2 cell lines. Arch Immunol Ther Exp (1996) 44:51-6.

140. Zimecki M, Artym J, Kocieba M, Kruzel M. Effects of lactoferrin on elicitation of the antigen-specific cellular and humoral cutaneous response in mice. Postepy Hig Med Dosw (2012) 66:16-22. doi:10.5604/17322693.975145

141. Yin H, Cheng L, Agarwal C, Agarwal R, Ju C. Lactoferrin protects against concanavalin A-induced liver injury in mice. Liver Int (2010) 30:623-32. doi:10.1111/j.1478-3231.2009.02199.x

142. Koike D, Makino I. Protective effect of lactoferrin on caerulein-induced acute pancreatitis in rats. Digestion (1993) 54:84-90. doi:10.1159/000201018

143. Cornish J, Callon KE, Naot D, Palmano KP, Banovic T, Bava U, et al. Lactoferrin is a potent regulator of bone cell activity and increases bone formation in vivo. Endocrinology (2004) 145:4366-74. doi:10.1210/en.2003-1307

144. Hou JM, Xue Y, Lin QM. Bovine lactoferrin improves bone mass and microstructure in ovariectomized rats via OPG/RANKL/RANK pathway. Acta Pharmacol Sin (2012) 33:1277-84. doi:10.1038/aps.2012.83

145. Inamori M, Togawa J, Matsumoto S, Harad K, Matsuura M, Iida H, et al. Protective effect of lactoferrin on acute acid reflux-induced esophageal mucosal damage. Hepatogastroenterology (2014) 61:1595-600.

146. Machnicki M, Zimecki M, Zagulski T. Lactoferrin regulates the release of tumour necrosis factor alpha and interleukin 6 in vivo. Int J Exp Pathol (1993) 74:433-9.

147. Hwang SA, Wilk KM, Budnicka M, Olsen M, Bangale YA, Hunter RL, et al. Lactoferrin enhanced efficacy of the BCG vaccine to generate host protective responses against challenge with virulent Mycobacterium tuberculosis. Vaccine (2007) 25:6730-43. doi:10.1016/j.vaccine.2007.07.005

148. Hwang S-A, Kruzel ML, Actor JK. Oral recombinant human or mouse lactoferrin reduces Mycobacterium tuberculosis TDM induced granulomatous lung pathology. Biochem Cell Biol (2017) 95(1):148-54. doi:10.1139/ bcb-2016-0061

149. Naidu AS, Arnold RR. Lactoferrin interaction with salmonellae potentiates antibiotic susceptibility in vitro. Diagn Microbiol Infect Dis (1994) 20:69-75. doi:10.1016/0732-8893(94)90094-9

150. Fowler CE, Soothill JS, Oakes L. MICs of rifampicin and chloramphenicol for mucoid Pseudomonas aeruginosa strains are lower when human lactoferrin is present. J Antimicrob Chemother (1997) 40:877-9. doi:10.1093/jac/40.6.877

151. Sanchez MS, Watts JL. Enhancement of the activity of novobiocin against Escherichia coli by lactoferrin. J Dairy Sci (1999) 82:494-9. doi:10.3168/jds. S0022-0302(99)75259-8

152. Zimecki M, Artym J, Kocieba M, Weber-Dabrowska B, Lusiak-Szelachowska M, Gorski A. The concerted action of lactoferrin and bacteriophages in the clearance of bacteria in sublethally infected mice. Postepy Hig Med Dosw (2008) 62:42-6.

153. Ochoa TJ, Cleary TG. Effect of lactoferrin on enteric pathogens. Biochimie (2009) 91:30-4. doi:10.1016/j.biochi.2008.04.006

154. Berlutti F, Pantanella F, Natalizi T, Frioni A, Paesano R, Polimeni A, et al. Antiviral properties of lactoferrin-a natural immunity molecule. Molecules (2011) 16:6992-7018. doi:10.3390/molecules16086992

155. Valenti P, Antonini G. Lactoferrin: an important host defence against microbial and viral attack. Cell Mol Life Sci (2005) 62:2576-87. doi:10.1007/ s00018-005-5372-0

156. Hwang SA, Kruzel ML, Actor JK. Immunomodulatory effects of recombinant lactoferrin during MRSA infection. Int Immunopharmacol (2014) 20:157-63. doi:10.1016/j.intimp.2014.02.029

Conflict of Interest Statement: The authors declare that the research was conducted in the absence of any commercial or financial relationships that could be construed as a potential conflict of interest.

Copyright $\odot 2017$ Kruzel, Zimecki and Actor. This is an open-access article distributed under the terms of the Creative Commons Attribution License (CC BY). The use, distribution or reproduction in other forums is permitted, provided the original author(s) or licensor are credited and that the original publication in this journal is cited, in accordance with accepted academic practice. No use, distribution or reproduction is permitted which does not comply with these terms. 